\title{
The dependence of radiative forcing and feedback on evolving patterns of surface temperature change in climate models
}

Article

Published Version

Andrews, T., Gregory, J. M. and Webb, M. J. (2015) The dependence of radiative forcing and feedback on evolving patterns of surface temperature change in climate models. Journal of Climate, 28 (4). pp. 1630-1648. ISSN 1520-0442 doi: https://doi.org/10.1175/JCLI-D-14-00545.1 Available at https://centaur.reading.ac.uk/38318/

It is advisable to refer to the publisher's version if you intend to cite from the work. See Guidance on citing.

To link to this article DOI: http://dx.doi.org/10.1175/JCLI-D-14-00545.1

Publisher: American Meteorological Society

All outputs in CentAUR are protected by Intellectual Property Rights law, including copyright law. Copyright and IPR is retained by the creators or other copyright holders. Terms and conditions for use of this material are defined in the End User Agreement.

www.reading.ac.uk/centaur 
Central Archive at the University of Reading

Reading's research outputs online 


\title{
The Dependence of Radiative Forcing and Feedback on Evolving Patterns of Surface Temperature Change in Climate Models
}

\author{
TIMOTHY ANDREWS \\ Met Office Hadley Centre, Exeter, United Kingdom \\ JONATHAN M. GREGORY \\ Met Office Hadley Centre, Exeter, and NCAS-Climate, University of Reading, Reading, United Kingdom \\ MARK J. WEBB \\ Met Office Hadley Centre, Exeter, United Kingdom
}

(Manuscript received 5 August 2014, in final form 30 October 2014)

\begin{abstract}
Experiments with $\mathrm{CO}_{2}$ instantaneously quadrupled and then held constant are used to show that the relationship between the global-mean net heat input to the climate system and the global-mean surface air temperature change is nonlinear in phase 5 of the Coupled Model Intercomparison Project (CMIP5) atmosphereocean general circulation models (AOGCMs). The nonlinearity is shown to arise from a change in strength of climate feedbacks driven by an evolving pattern of surface warming. In 23 out of the 27 AOGCMs examined, the climate feedback parameter becomes significantly ( $95 \%$ confidence) less negative (i.e., the effective climate sensitivity increases) as time passes. Cloud feedback parameters show the largest changes. In the AOGCM mean, approximately $60 \%$ of the change in feedback parameter comes from the tropics $\left(30^{\circ} \mathrm{N}-30^{\circ} \mathrm{S}\right)$. An important region involved is the tropical Pacific, where the surface warming intensifies in the east after a few decades. The dependence of climate feedbacks on an evolving pattern of surface warming is confirmed using the HadGEM2 and HadCM3 atmosphere GCMs (AGCMs). With monthly evolving sea surface temperatures and sea ice prescribed from its AOGCM counterpart, each AGCM reproduces the timevarying feedbacks, but when a fixed pattern of warming is prescribed the radiative response is linear with global temperature change or nearly so. It is also demonstrated that the regression and fixed-SST methods for evaluating effective radiative forcing are in principle different, because rapid SST adjustment when $\mathrm{CO}_{2}$ is changed can produce a pattern of surface temperature change with zero global mean but nonzero change in net radiation at the top of the atmosphere $\left(\sim-0.5 \mathrm{~W} \mathrm{~m}^{-2}\right.$ in HadCM 3$)$.
\end{abstract}

\section{Introduction}

Earth's global energy balance provides a convenient framework for describing and predicting climate change. Changes to this balance caused by an external factor are termed "radiative forcings" (e.g., Shine and Forster 1999). The magnitude of climate change in response to a radiative forcing is determined by heat uptake and various climate feedbacks that amplify or dampen the initial perturbation, such as changes in clouds, sea ice, and water vapor (e.g., Soden and Held 2006).

Corresponding author address: Timothy Andrews, Met Office Hadley Centre, FitzRoy Road, Exeter EX13PB, United Kingdom. E-mail: timothy.andrews@metoffice.gov.uk
The value of the forcing-response framework is underpinned by a simple linear relationship (e.g., Gregory et al. 2004) between global radiative forcing $(F$; in $\left.\mathrm{W} \mathrm{m}^{-2}\right)$; heat uptake $\left(N\right.$; in $\left.\mathrm{W} \mathrm{m}^{-2}\right)$, which is overwhelmingly into the ocean (e.g., Church et al. 2011); and surface air temperature change $(\Delta T$; in $\mathrm{K})$, so that

$$
N=F+\alpha \Delta T,
$$

where $\alpha\left(\mathrm{W} \mathrm{m}^{-2} \mathrm{~K}^{-1}\right)$ is the climate feedback parameter. This forcing-feedback framework assumes $\alpha$ to be constant, so that variations in earth's global energy budget $(N)$ are linear with $\Delta T$ in any scenario where $F$ is constant (such as abrupt $\mathrm{CO}_{2}$ quadrupling experiments). Note that the sign convention is the opposite of that 
(a) $\mathrm{HadCM} 3$



(c) CMIP5 AOGCM-mean

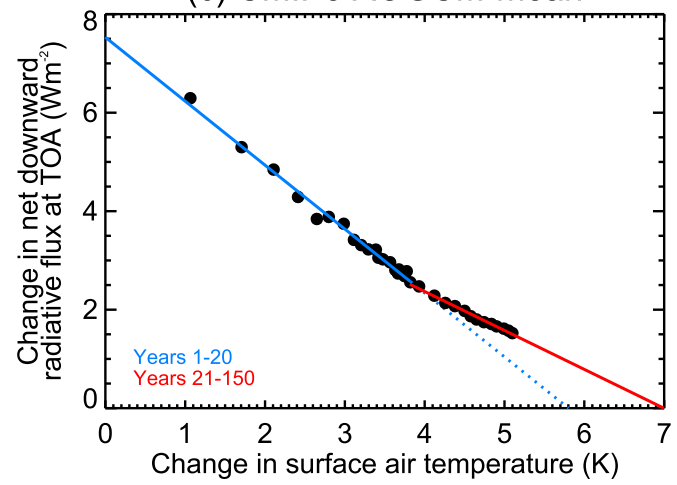

(b) HadGEM2-ES

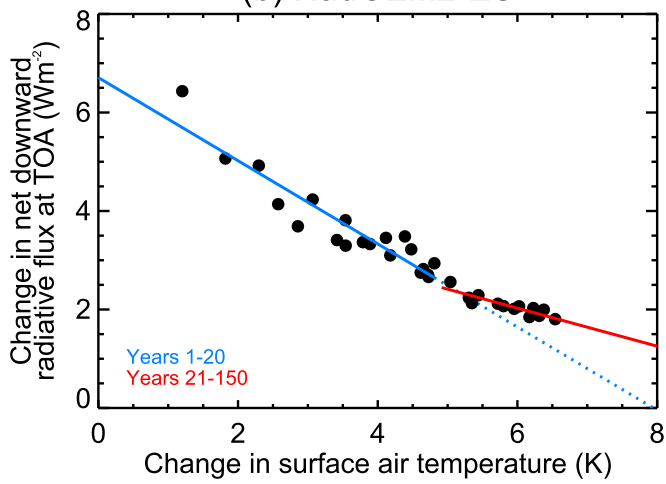

(d) Feedback Parameter



FIG. 1. Abrupt $4 \mathrm{xCO}_{2}$ Gregory plot ( $N$ as a function of $\Delta T$ ) for (a) HadCM3, (b) HadGEM2-ES, and (c) the CMIP5 AOGCM mean. Lines show regression fits to the global annual-mean data points for years 1-20 (blue) and subsequent years (red). The plots show global annual-mean data for the first $20 \mathrm{yr}$, followed by decadal means. The slope and $N$ intercept $(\Delta T=0)$ give the feedback parameter $\left(\alpha ; \mathrm{W} \mathrm{m}^{-2} \mathrm{~K}^{-1}\right)$ and effective radiative forcing $\left(F ; \mathrm{W} \mathrm{m}^{-2}\right)$, respectively. The $\Delta T$ intercept $(N=0)$ estimates the equilibrium response assuming the feedback strengths remain unchanged. The blue dotted line represents the path the AOGCM would have taken to equilibrium if it had maintained the feedback strengths as simulated during the early years of the experiment. (d) Comparison of the net feedback parameter $(\alpha)$ diagnosed from the early (years 1-20) and subsequent (years 21-150) years. The length (blue) and width (red) of the symbols in (d) represent their 95\% confidence intervals (estimated by 1.96 standard deviations from the regression).

followed by Gregory et al. (2004) and Andrews et al. (2012a); Eq. (1) requires that $\alpha<0$ for the system to be stable under perturbations.

The paradigm was first applied to equilibrium states, such as $\mathrm{CO}_{2}$ doubling $\left(2 \mathrm{xCO}_{2}\right)$ scenarios that use an atmospheric general circulation model (AGCM) coupled to a simple thermodynamic mixed layer ("slab") ocean model (i.e., with prescribed ocean heat transport). More recently, a constant $\alpha$ has been found to be an excellent approximation under this idealized experimental design during transient climate change, as demonstrated by a linear dependence of $N$ on $\Delta T$ in $2 \mathrm{xCO}_{2}$ experiments (e.g., Gregory and Webb 2008).

In contrast to idealized model studies of climate sensitivity, real-world climate forcing and change are time dependent and involve nonlinear coupled atmosphereocean processes and heat exchanges between the ocean mixed layer and deep ocean that require an AOGCM (i.e., with a 3D dynamic ocean model) to simulate. The linearity of Eq. (1) is found to be less robust in AOGCM climate change simulations (see Fig. 1; Gregory et al. 2004; Andrews et al. 2012a; Armour et al. 2013; Geoffroy et al. 2013; Block and Mauritsen 2013), which we interpret as a nonconstant $\alpha$, though other interpretations can be drawn (see below). Nonetheless, we note that linearity is a surprisingly good approximation for some AOGCMs (e.g., Danabasoglu and Gent 2009; Andrews et al. 2012a).

Recent work describing the time-dependent response of AOGCMs has focused on developing new conceptual frameworks fitted to AOGCM results. Winton et al. (2010), Held et al. (2010), and Geoffroy et al. (2013) used a two-layer ocean model (approximating a mixed layer and deep-ocean response) and an "ocean heat 
uptake efficacy" term to describe the evolution of $N$ and $\Delta T$. Armour et al. (2013) proposed a constant regional feedback framework convolved with an evolving pattern of surface warming. However, these frameworks involve simplifications that have not yet been thoroughly tested. Limitations of the regional feedback approach have been described by Rose et al. (2014) and are also seen here in sections 2 and 3 and of the two-layer ocean model by Bouttes et al. (2013). Therefore, we tackle the issue from a different angle. Rather than trying to fit or quantify the nonlinear behavior within a simplified framework, we use model diagnostics and an innovative experimental design to investigate why the AOGCMs behave as they do.

The inconstancy of $\alpha$ could come from a number of sources. First, some climate feedbacks will depend on climate state (characterized by global $T$ ). For example, sea ice and land-snow-cover feedbacks will diminish as the climate system warms enough for the ice and snow coverage to have retreated (e.g., Colman and McAvaney 2009). Second, some climate feedbacks have their own time scale not closely tied to $\Delta T$, such as changes in vegetation or soil moisture. Finally, some climate feedbacksparticularly cloud feedbacks-may be sensitive to an evolving pattern of surface warming (e.g., Senior and Mitchell 2000; Held et al. 2010; Andrews et al. 2012a; Armour et al. 2013; Andrews and Ringer 2014; Rose et al. 2014).

Andrews et al. (2012a) and Geoffroy et al. (2013) examined the linearity of $N$ as a function of $\Delta T$ across CMIP5 AOGCMs forced by an abrupt quadrupling of atmospheric $\mathrm{CO}_{2}$ levels. The purpose of this paper is to go further: Sections 2 and 3 examine the robustness of nonlinearity across a larger set of CMIP5 models than was previously available and develops a physical understanding of the underlying mechanisms. Section 4 introduces an experimental design that uses AGCMs to reproduce the nonlinear behavior of their corresponding AOGCM and then test the sensitivity of $\alpha$ to evolving sea surface temperature patterns. Section 5 investigates how the effective radiative forcing arises. In section 6 , the behavior of climate feedback is further examined in a long (over 1000 yr) HadGEM2-ES simulation. Finally, section 7 discusses the implications of the nonlinearity in the $N$ versus $\Delta T$ relationship.

\section{Evolving feedbacks in CMIP5 models}

\section{a. Nonlinear dependence of radiative fluxes on $\Delta T$}

We illustrate the nonlinear dependence of $N$ on $\Delta T$ in Fig. 1 for an abrupt $4 \mathrm{xCO}_{2}$ scenario for the CMIP5 AOGCM mean (see Table 1 for individual models), as well as separately for the AOGCMs HadCM3 and
HadGEM2-ES, which we use for a further analysis in section 4 . We approximate the data with two ordinary least squares (OLS) regression fits, separated at year 20. The choice of year 20 approximately separates the fast and slow components of the climate response (Held et al. 2010; Geoffroy et al. 2013). Note that this choice is somewhat arbitrary, but our purpose is not to best fit the nonlinear behavior; rather, it is to illustrate that the slope (the feedback parameter) changes during the simulation. Whether the separation is chosen at $5,10,15$, or $20 \mathrm{yr}$ does not affect this conclusion. Geoffroy et al. (2013) provide an optimal method assuming a two-layer ocean model for determining a point of separation if required. Note that for clarity all the figures show decadal means after the first $20 \mathrm{yr}$, but all calculations use annual means and we treat all points as independent in the regressions.

Figure 1a shows the results from a seven-member ensemble of 100-yr HadCM3 simulations. The value of the ensemble is to demonstrate that the curvature (at least in this individual model) is not a statistical artefact of unforced interannual variability; it is present in all ensemble members and very clear in the ensemble mean. We compare the feedback parameter derived from the first $20 \mathrm{yr}$ against the remaining years in Table 1 and Fig. 1d for the individual CMIP5 AOGCMs. Deviations from the 1:1 line imply a nonlinearity. In 23 out of 27 CMIP5 models examined, the net feedback parameter becomes significantly ( $95 \%$ confidence) less negative as the simulation progresses (Table 1 and Fig. 1d; i.e., in Fig. 1d the points mostly lie below the 1:1 line).

For a given $N$ the warming implied by the feedbacks from the first $20 \mathrm{yr}$ understates the actual warming simulated by the models on longer (multidecadal to centennial) time scales (cf. dotted blue and thick red lines in Figs. 1a-c). Extrapolating to $N=0$ (equal to $-F / \alpha$ ) estimates the equilibrium $\Delta T$ (Gregory et al. 2004). If the forcing is doubled $\mathrm{CO}_{2}$ then this is referred to as the "effective climate sensitivity," since it is the estimated equilibrium response to $2 \mathrm{xCO}_{2}$ from a transient AOGCM simulation assuming constant feedback strengths. This calculation of effective climate sensitivity differs slightly from that originally defined by Murphy (1995) and Senior and Mitchell (2000), who first estimated $\alpha$ by assuming $F$ : that is, $\alpha=(N-F) / \Delta T$. Williams et al. (2008) showed how an incorrect $F$ can lead to spurious time variations in $\alpha$ and the effective climate sensitivity. Figure 2 shows the effective climate sensitivity, given by $-F / 2 \alpha$, which is half of the $\Delta T$ intercept, noting that the factor of $1 / 2$ follows because $\mathrm{CO}_{2}$ forcing is approximately logarithmic with $\mathrm{CO}_{2}$ concentration, for each CMIP5 model as determined from the early (years 1-20) and subsequent (years 21-150) years of the simulation. In nearly all CMIP5 models, the effective climate sensitivity increases during the simulation. 
TABLE 1. Feedback parameters $(\alpha)$ in $\mathrm{W} \mathrm{m}^{-2} \mathrm{~K}^{-1}$ for the HadCM3 and CMIP5 AOGCMs as diagnosed from years 1-20 and 21-150 (21-100 for HadCM3) of the abrupt $4 \mathrm{xCO}_{2}$ simulation and the radiative components [LW and SW clear sky, and cloud radiative effect (CRE)]. Values are diagnosed from the slope of the ordinary least squares regression of the change in global annual-mean radiative flux against $\Delta T$. The CMIP5-mean AOGCM shows the coefficients from Figs. 1c and 3a.

\begin{tabular}{|c|c|c|c|c|c|}
\hline \multirow[b]{2}{*}{ AOGCM } & \multicolumn{5}{|c|}{ Feedback parameters $(\alpha)$ for years $1-20(121-150)\left(\mathrm{W} \mathrm{m}^{-2} \mathrm{~K}^{-1}\right)$} \\
\hline & Net & LW clear sky & SW clear sky & LW CRE & SW CRE \\
\hline ACCESS1.0 & $-1.08(-0.57 *)$ & $-1.70(-1.64)$ & $0.65\left(0.86^{*}\right)$ & $0.17(0.07 *)$ & $-0.21\left(0.14^{*}\right)$ \\
\hline ACCESS1.3 & $-1.17(-0.49 *)$ & $-1.89\left(-1.77^{*}\right)$ & $0.80(0.79)$ & $-0.10(-0.09)$ & $0.03(0.57 *)$ \\
\hline BCC-CSM1.1(m) & $-1.22(-0.89 *)$ & $-1.96(-1.92)$ & $0.70(0.86 *)$ & $-0.04(0.31 *)$ & $0.07(-0.14)$ \\
\hline BCC-CSM1.1 & $-1.43\left(-0.85^{*}\right)$ & $-1.89(-1.87)$ & $0.70\left(0.98^{*}\right)$ & $0.21(0.27)$ & $-0.46(-0.24 *)$ \\
\hline BNU-ESM & $-0.86(-0.97)$ & $-1.70(-1.68)$ & $1.17(1.05)$ & $0.18(0.20)$ & $-0.51(-0.54)$ \\
\hline CanESM2 & $-1.19(-0.91)$ & $-1.93(-1.86)$ & $0.66(0.76)$ & $0.47(0.42)$ & $-0.39(-0.23)$ \\
\hline CCSM4 & $-1.52(-0.94 *)$ & $-1.99(-1.91)$ & $0.84(0.89)$ & $0.10(0.11)$ & $-0.47(-0.04 *)$ \\
\hline CNRM CM5 & $-1.05(-1.23)$ & $-1.79(-1.76)$ & $0.96\left(0.56^{*}\right)$ & $0.18(-0.00 *)$ & $-0.40\left(-0.03^{*}\right)$ \\
\hline CSIRO Mk3.6.0 & $-1.09(-0.41 *)$ & $-1.85(-1.64 *)$ & $0.68\left(0.86^{*}\right)$ & $-0.19(-0.13)$ & $0.28(0.51)$ \\
\hline FGOALS-g2 & $-1.32(-0.62 *)$ & $-1.77(-1.73)$ & $0.74\left(1.14^{*}\right)$ & $0.09\left(0.19^{*}\right)$ & $-0.38(-0.22 *)$ \\
\hline GFDL CM3 & $-1.13(-0.60 *)$ & $-2.03(-1.92)$ & $0.65(0.67)$ & $-0.02(-0.03)$ & $0.27\left(0.68^{*}\right)$ \\
\hline GFDL-ESM2G & $-1.58(-0.73 *)$ & $-1.54\left(-1.76^{*}\right)$ & $0.55\left(0.78^{*}\right)$ & $0.39(0.07 *)$ & $-0.98\left(0.19^{*}\right)$ \\
\hline GFDL-ESM2M & $-1.36(-1.13)$ & $-1.59(-1.77 *)$ & $0.65(0.67)$ & $0.37\left(-0.03^{*}\right)$ & $-0.79(0.00 *)$ \\
\hline GISS-E2-H & $-1.90(-1.47 *)$ & $-1.74(-1.62 *)$ & $0.50(0.51)$ & $0.23\left(0.36^{*}\right)$ & $-0.89(-0.71)$ \\
\hline GISS-E2-R & $-2.37(-1.33 *)$ & $-1.78(-1.57 *)$ & $0.36(0.42)$ & $0.23\left(0.40^{*}\right)$ & $-1.18\left(-0.58^{*}\right)$ \\
\hline HadCM3 & $-1.25(-0.74 *)$ & $-1.84(-1.71 *)$ & $0.58(0.59)$ & $0.37\left(0.45^{*}\right)$ & $-0.35\left(-0.06^{*}\right)$ \\
\hline HadGEM2-ES & $-0.81(-0.35 *)$ & $-1.81(-1.64 *)$ & $1.05\left(0.76^{*}\right)$ & $0.20\left(0.11^{*}\right)$ & $-0.25\left(0.44^{*}\right)$ \\
\hline INM-CM4 & $-1.67(-1.22 *)$ & $-2.00(-1.89)$ & $0.71(0.52 *)$ & $-0.02(0.18)$ & $-0.36(-0.04)$ \\
\hline IPSL-CM5A-LR & $-0.86(-0.57 *)$ & $-2.04(-1.92 *)$ & $0.59(0.55)$ & $0.01(0.11)$ & $0.58(0.69)$ \\
\hline IPSL-CM5B-LR & $-1.15(-0.73 *)$ & $-1.89(-1.82)$ & $0.69(0.62)$ & $-0.03\left(0.13^{*}\right)$ & $0.09(0.34)$ \\
\hline MIROC-ESM & $-1.06(-0.64 *)$ & $-1.90(-1.99 *)$ & $1.03(0.57 *)$ & $0.24\left(-0.25^{*}\right)$ & $-0.44\left(1.03^{*}\right)$ \\
\hline MIROC5 & $-1.73(-1.19 *)$ & $-1.94(-1.77 *)$ & $0.73(0.86 *)$ & $-0.17(0.14 *)$ & $-0.36(-0.43)$ \\
\hline MPI-ESM-LR & $-1.33(-0.90 *)$ & $-1.87(-1.74 *)$ & $0.61(0.71 *)$ & $0.06\left(0.26^{*}\right)$ & $-0.12(-0.13)$ \\
\hline MPI-ESM-MR & $-1.40(-0.82 *)$ & $-1.89\left(-1.78^{*}\right)$ & $0.62(0.80 *)$ & $0.02\left(0.26^{*}\right)$ & $-0.14(-0.10)$ \\
\hline MPI-ESM-P & $-1.58\left(-0.96^{*}\right)$ & $-1.92\left(-1.75^{*}\right)$ & $0.59(0.68)$ & $0.05\left(0.22^{*}\right)$ & $-0.31(-0.10)$ \\
\hline MRI-CGCM3 & $-1.54\left(-1.06^{*}\right)$ & $-2.05(-1.93)$ & $0.62(0.77 *)$ & $-0.36(-0.28)$ & $0.25(0.39)$ \\
\hline NorESM1-M & $-1.63(-0.83 *)$ & $-1.90(-1.81)$ & $0.69(0.90 *)$ & $-0.04(0.10)$ & $-0.39\left(-0.03^{*}\right)$ \\
\hline CMIP5 mean & $-1.30(-0.79 *)$ & $-1.86(-1.77 *)$ & $0.74(0.77)$ & $0.09(0.09)$ & $-0.27(0.27 *)$ \\
\hline
\end{tabular}

* Indicates a significant change in slope at the $95 \%$ confidence interval obtained by testing whether $\left|\alpha_{a}-\alpha_{b}\right|>1.96\left(\sigma_{a}^{2}+\sigma_{b}^{2}\right)^{1 / 2}$, where $\sigma_{a}$ and $\sigma_{b}$ are the standard deviations from the regression associated with slope $\alpha_{a}$ (years 1-20) and $\alpha_{\mathrm{b}}$ (subsequent years).

To understand which feedback components drive the nonlinearity we plot the individual longwave (LW) and shortwave (SW) clear sky (clouds artificially removed from the radiation call) and cloud radiative effect [CRE; defined as the difference between all sky (i.e., with clouds if present) and clear sky] downward radiative fluxes as a function of $\Delta T$ (Fig. 3a) for the CMIP5 multimodel mean. We compare the components of the feedback parameter derived from the first $20 \mathrm{yr}$ against the remaining years in Table 1 and Fig. $3 b$ for the individual CMIP5 models. As in Eq. (1), the sign convention is that the parameter is positive for feedbacks which tend to increase climate warming.

Variation of outgoing LW clear-sky radiation with $\Delta T$ (the combined effect of the Planck, water vapor, and lapse-rate feedbacks) dominates the net (negative) feedback (Table 1). As $\Delta T$ increases, this contribution to $N$ shows a small but largely robust shallowing of its slope (i.e., the net LW clear-sky feedback parameter become less negative) across models. This is consistent with
Meraner et al. (2013), who argued that the (positive) water vapor feedback should strengthen as the climate warms, though we cannot definitively attribute the LW clear-sky curvature to this.

Although the LW clear-sky gives the largest contribution to the net feedback parameter, the largest contribution to the change in the feedback parameter with $\Delta T$ comes from the SW CRE feedback (Figs. 3a,b and Table 1; note the change in slope of the SW CRE line in Fig. 3a and the large deviations below the 1:1 line in Fig. 3b). This suggests a change in strength of SW cloud feedback processes (further analyzed in section $2 b$ ). LW CRE (which is mostly influenced by high clouds) and SW clear-sky (which is mostly influenced by surface albedo and noncloud atmospheric SW absorption and scattering) radiative fluxes are largely linear with $\Delta T$ in CMIP5 models. Where significant deviations do exist (Table 1), they tend to be small and there is no robust direction of change across models (Table 1 and Fig. 3). 




FIG. 2. Comparison of the effective climate sensitivity (ECS) for individual CMIP5 models as estimated from the early (years 1-20) and subsequent (years 21-150) years of the abrupt $4 \mathrm{xCO}_{2}$ AOGCM simulations. ECS is calculated as $-F / 2 \alpha$, where $F$ and $\alpha$ are determined from the linear regression of $N$ against $\Delta T$ in the relevant time periods of the experiments.

Figure 4 shows the local contribution to the CMIP5mean global results: that is, the geographical distribution of feedback parameters as derived from the early (years 1-20) and long-term (years 21-150) parts of the simulation (calculated by regressing the change in local topof-atmosphere radiative fluxes against global-mean $\Delta T$ ). The change in geographical distribution of the feedback parameter is shown on the right-hand side. Note that the $\mathrm{BCC}$ and $\mathrm{BNU}$ models are excluded from this regional analysis since they introduced singularities near the poles.

The pattern of decreasing (more positive) feedback parameter (Fig. 4, top right) is largely dominated by the change in net (LW + SW) CRE feedback. The correlation coefficient between these two patterns (area weighted) is 0.6 , compared to only 0.3 for the change in clear-sky terms to the change in total feedback parameter. The change in feedback pattern highlights large positive changes in the equatorial Pacific, the east tropical Pacific (regions important for low cloud stratocumulus decks which form over the relatively cold SSTs associated with ocean upwelling), and the Southern Ocean storm tracks, though these are clearly not the only regions that contribute to the curvature (Fig. 4).

Approximately $60 \%$ of the change in AOGCM-mean global net CRE and total net feedback comes from the tropics $\left(30^{\circ} \mathrm{N}-30^{\circ} \mathrm{S}\right)$. The remaining $40 \%$ suggests a less dominant, though clearly still important, role for changes in the strength of extratropical feedbacks. The change in net CRE feedback can be further traced to a change in the patterns of SW and LW CRE feedbacks, which additionally show more widespread changes across the tropical Pacific that cancel in the net CRE (Fig. 4): a wellknown result from changes in high clouds which have opposing LW and SW effects (e.g., Kiehl 1994).

These findings are in contrast to those of Armour et al. (2013), who emphasized a larger role for noncloud highlatitude feedbacks in causing time variation in the feedback parameter of CCSM4. We cannot reconcile their results with ours since virtually all of the curvature in CCSM4 comes from a change in SW CRE feedback parameter in our analysis; the SW clear-sky feedback parameter-where changes in sea ice feedbacks will have the largest impact-shows no change (Table 1). We presume Armour et al. (2013) did not observe the time variation in the SW cloud feedback parameter either because of limitations imposed by their fixed local feedback framework (see section 3; Rose et al. 2014) or because they did not separate cloud adjustments from cloud feedbacks in their analysis. We also note that our focus is on the $150 \mathrm{yr}$ of CMIP5-type simulations; highlatitude responses may strengthen or weaken on longer (multicentennial) time scales (e.g., Senior and Mitchell 2000; Li et al. 2013; section 6).

\section{b. Cloud masking and SW APRP}

Attributing changes in CRE to change in clouds requires caution because of "cloud masking" effects of the clear-sky fluxes (e.g., Soden et al. 2004, 2008). For example, the sea ice feedback is larger under clear skies (since clouds will mask, at the TOA or tropopause, the radiative effects of any sea ice change); hence, defining the CRE as all-sky minus clear-sky downward fluxes will give nonzero CRE changes without any change in cloud properties.

Large negative SW CRE changes at high latitudes are likely due to the cloud masking effects of sea ice changes, indicated by a positive contribution from the SW clearsky feedbacks in both polar regions. The poleward shift of the sea ice feedback is clear in the SW clear-sky feedbacks. For example, in years 1-20 there is a large positive feedback in the SW clear-sky fluxes north and west of the Aleutian Islands, not present in the years 21-150 regression. Similarly, the large positive SW clearsky feedbacks around Antarctica retreat poleward, though it tends to increase where sea ice still exists.

We do not believe cloud masking has any impact on our conclusion that changes in cloud feedbacks are the main driver of the nonlinear behavior. This is because (i) the global clear-sky fluxes are largely linear, especially the SW; (ii) the dominant change in the geographical pattern of the feedback parameter picks out regions important for cloud feedback, not sea ice changes (i.e., the SW CRE changes at low and middle latitudes cannot be due to masking of sea ice); and finally (iii) Zelinka 
(a) CMIP5-mean Radiative Components

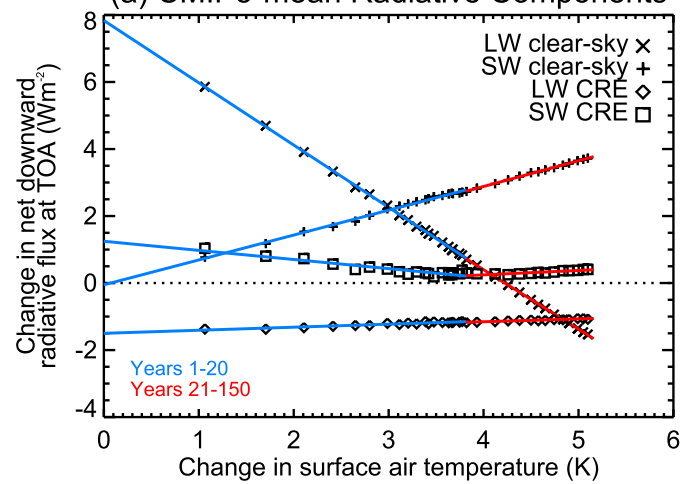

(c) CMIP5-mean SW APRP

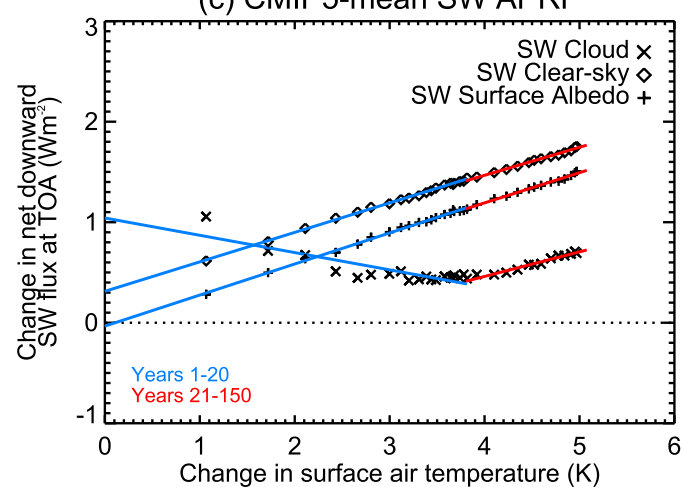

(b) CMIP5 Feedback Components



(d) SW APRP Feedback Components

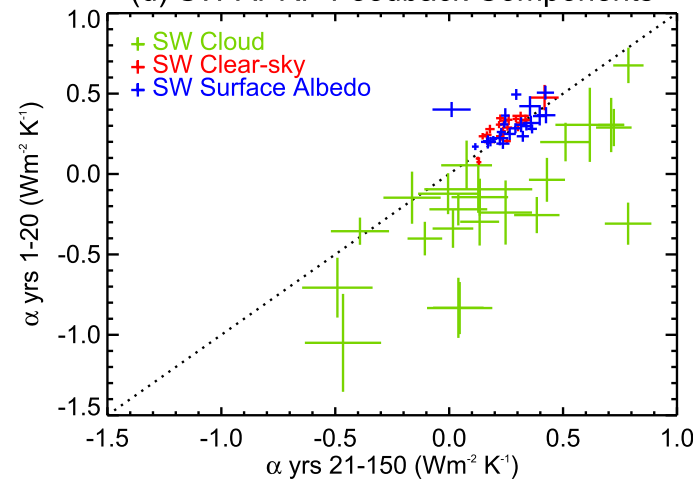

FIG. 3. (a) Radiative components of the CMIP5 4xCO $\mathrm{xOOGCM}_{2}$-mean Gregory plot, with linear fits separated over two periods: years 1-20 (blue) and years 21-150 (red). Points show global annual means for years 1-20, followed by decadal means. (b) Comparison of the radiative feedback parameters determined from regression on short (years 1-20) and long (years 21-150) time scales for individual CMIP5 models. (c) CMIP5 AOGCM-mean cloud, noncloud (i.e., clear-sky atmospheric scattering and absorption), and surface albedo contributions to the SW radiation budget changes, as a function of $\Delta T$, as determined from the SW APRP method. (d) As in (b), but for the SW APRP component terms. The vertical length and horizontal width of the symbols in (b),(d) represent their $95 \%$ confidence intervals (estimated by 1.96 standard deviations from the regression).

et al. (2013) found global nonlinear behavior in cloud feedbacks using more sophisticated kernel techniques that avoid masking issues.

To corroborate our attribution of the SW feedback changes to cloud changes, we use the SW approximate partial radiative perturbation (SW APRP) technique (Taylor et al. 2007) applied to monthly-mean data to split the change in SW radiative fluxes into a contribution from surface albedo, cloud, and noncloud (i.e., clear-sky atmospheric scattering and absorption) components. Taylor et al. (2007) compared the SW APRP method against full PRP and found global-mean feedback calculations to agree well (errors on the order of $5 \%-10 \%$ ), concluding that APRP is an appropriate tool for calculating SW forcing and feedbacks in climate models. We exclude any data where the global annual-mean residual is greater than $0.1 \mathrm{~W} \mathrm{~m}^{-2}$. Figures 3c,d show the CMIP5 multimodel-mean regression of the SW APRP breakdown as a function of $\Delta T$ and the individual AOGCM short-term versus long-term feedback parameter results. It confirms that the curvature comes from cloud feedback changes and that the use of CRE is an adequate approximation for our purpose. It also confirms that global surface albedo and noncloud atmospheric scattering-absorption are well approximated as linear with $\Delta T$ for most models. Where curvature does exist in the noncloud terms, it is small (Fig. 3d). The one anomaly is INM-CM4, which has a near-zero surface albedo feedback on the longer time scale (years 21-150) (anomalous blue point in Fig. 3d), which is consistent with an anomalous evolution in its Northern Hemisphere polar amplification (next section).

The SW APRP analysis points to other largely underappreciated results: (i) changes in noncloud atmospheric absorption-scattering with $\Delta T$ (presumably the SW absorption component of the water vapor feedback) contribute approximately the same as surface albedo feedbacks to SW radiation budget changes and (ii) there is a considerable intercept and uncertainty in the clear-sky 


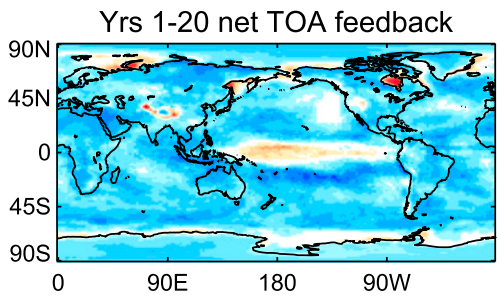

Yrs 1-20 Net CRE feedback

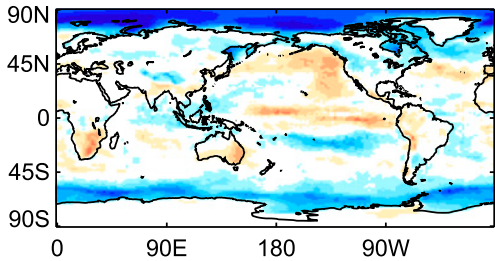

Yrs 1-20 LW clear-sky feedback

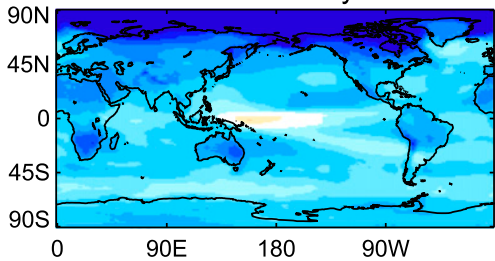

Yrs 1-20 SW clear-sky feedback

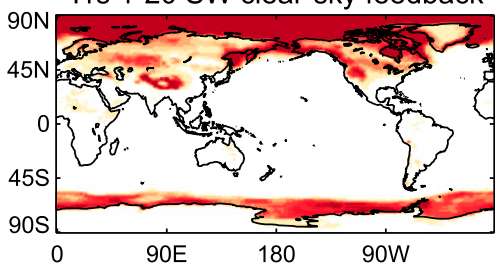

Yrs 1-20 LW CRE feedback

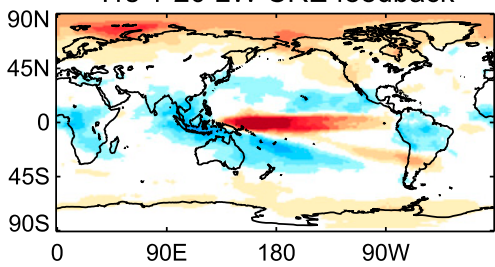

Yrs 1-20 SW CRE feedback



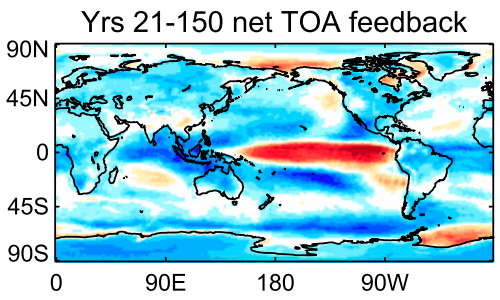

Yrs 21-150 Net CRE feedback

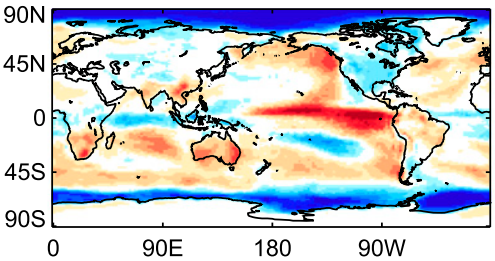

Yrs 21-150 LW clear-sky feedback

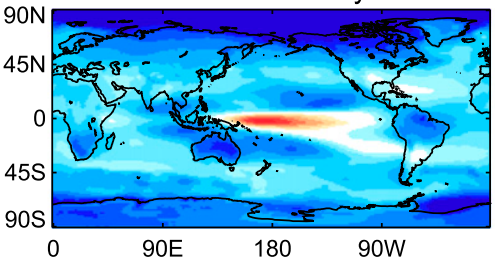

Yrs 21-150 SW clear-sky feedback

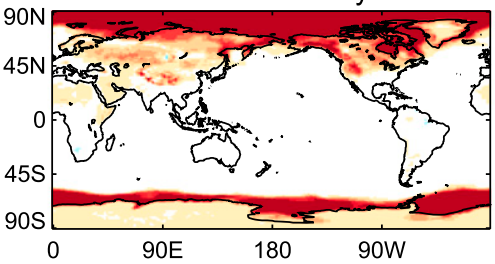

Yrs 21-150 LW CRE feedback

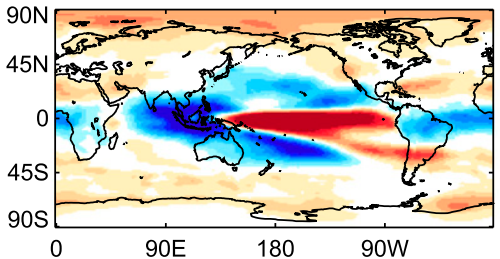

Yrs 21-150 SW CRE feedback

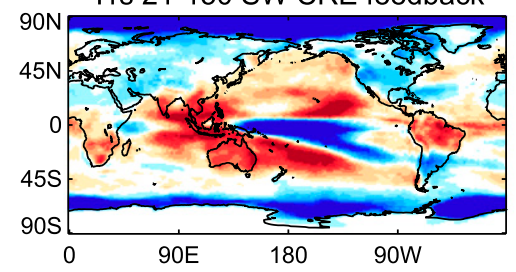

Change in net TOA feedback



Change in Net CRE feedback

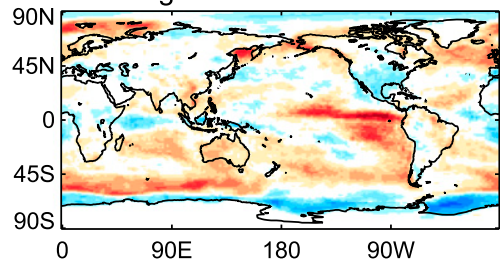

Change in LW clear-sky feedback



Change in SW clear-sky feedback



Change in LW CRE feedback

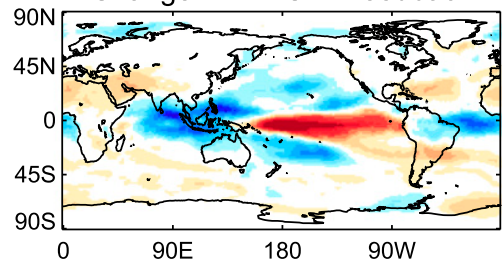

Change in SW CRE feedback

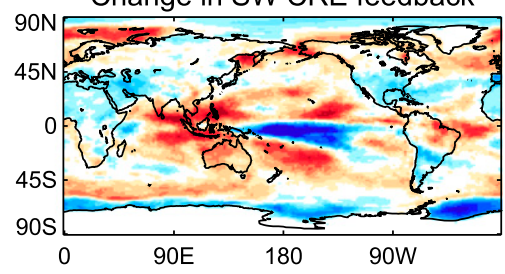

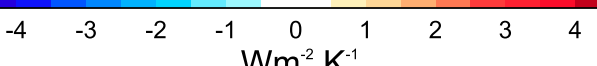

FIG. 4. Geographical distribution of the radiative feedback terms (top to bottom) net TOA, net CRE, LW clear-sky feedback, SW clear-sky feedback, LW cloud radiative effect, and SW cloud radiative effect, on (left) short (years 1-20) and (middle) long (years 21-150) time scales, and (right) their difference (long minus short), for the CMIP5 AOGCM mean. Plots are calculated from linear regression of local radiative fluxes against global $\Delta T$ over the relevant time periods. 
(a) Years 1-20 warming pattern

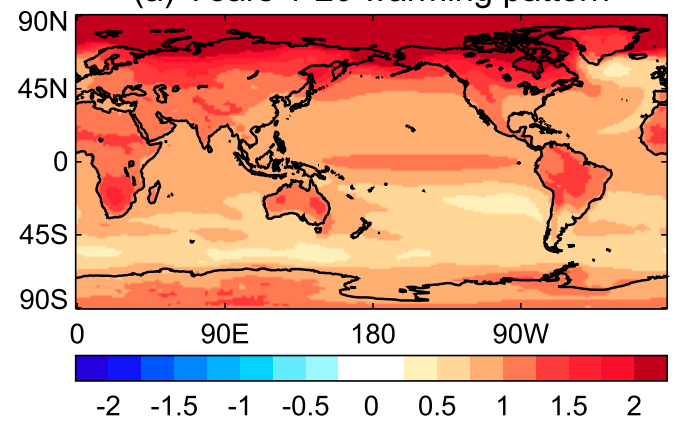

(b) Years 21-150 warming pattern

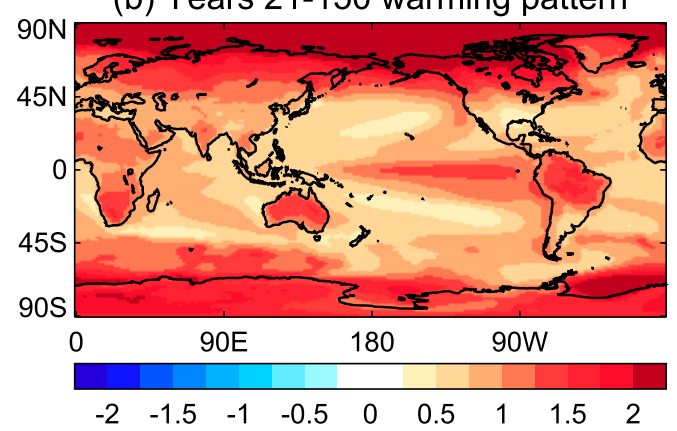

$(c)=(b)-(a)$ Change in warming pattern

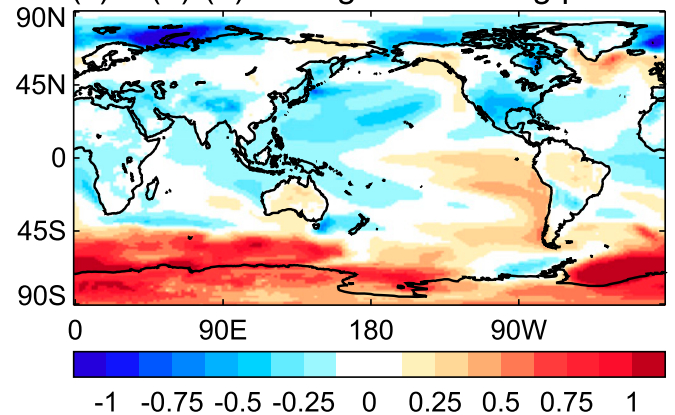

(d) Years 1-20 warming pattern

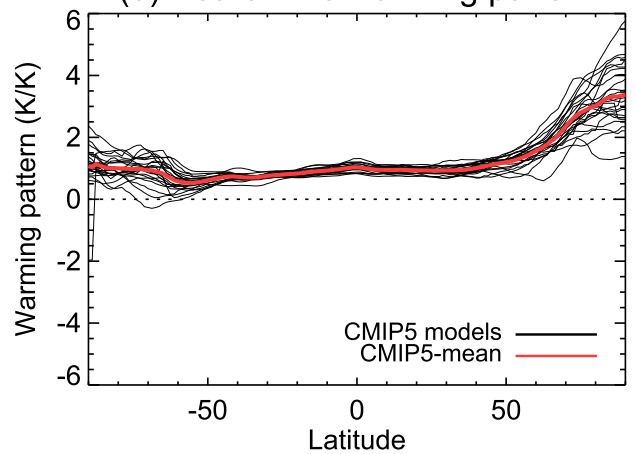

(e) Years 21-150 warming pattern


FIG. 5. Geographical distribution of the pattern of surface air temperature change for (a) years 1-20, (b) years 21150, and (c) their difference for the CMIP5 AOGCM mean. Plots show the slope of the linear regression of local $\Delta T$ against global $\Delta T$ for the relevant time periods and are dimensionless. By construction, the global mean of (a),(b) is unity, while (c) is zero. (d)-(f) The zonal-mean patterns (red lines), where thin lines are individual CMIP5 models.

scattering-absorption term $\left[\sim 0.3 \mathrm{~W} \mathrm{~m}^{-2}\right.$ in the CMIP5 multimodel mean, with a range (not shown) from $\sim 0.0$ to $1.0 \mathrm{~W} \mathrm{~m}^{-2}$ across models], which we interpret as the instantaneous SW absorption component of the $4 \mathrm{xCO}_{2}$ effective radiative forcing.

\section{An evolving pattern of surface warming in CMIP5 models}

This section considers how an evolving pattern of surface warming may drive the change in feedback strengths identified in section 2. Figure 5 shows the
CMIP5 AOGCM-mean surface warming pattern [determined from OLS regression of local $\Delta T$ against global $\Delta T$ (i.e., it is dimensionless: in $\mathrm{K} \mathrm{K}^{-1}$ ) and is unity in the global mean] for the first $20 \mathrm{yr}$ (Fig. 5a) and the remaining years (Fig. 5b). Figure $5 \mathrm{c}$ shows the change in pattern (i.e., Fig. $5 b$ - Fig. 5 a, which must be zero in the global mean by construction). The zonal-mean surface warming patterns for the individual models are shown in Figs. 5d-f. Note that, as with Fig. 4, the BCC and BNU models are excluded.

A large Northern Hemisphere (NH) polar amplification is well established early on in the simulation in all 
models examined (Figs. 5a,d): that is, the NH high latitudes warm more than the global mean. Subsequently, some models increase their $\mathrm{NH}$ polar amplification whereas some models reduce it (Figs. 5e,f). One model, INM-CM4, surprisingly has a negative polar amplification during years $21-150$ of the simulation. In contrast to the $\mathrm{NH}$, pronounced polar amplification in the Southern Hemisphere (SH) is not seen in the initial (years 1-20) part of the simulation but subsequently (years 21-150) increases in virtually all models (Figs. 5d-f).

The largest change in the zonal-mean warming pattern generally occurs at high latitudes across models, but the zonal-mean distributions do not reveal important shifts in the tropical warming pattern. Figure 5a shows a relatively uniform tropical Pacific warming pattern during years $1-20$, with some delayed warming in the east. In contrast, a strong east-west gradient then emerges after a few decades with a more pronounced warming pattern in the east Pacific compared to the west (Fig. 5b). The change in warming pattern (Fig. 5c) highlights the east tropical Pacific, the Southern Ocean, and Antarctica as regions where warming is more pronounced per degree global temperature change on longer time scales compared to the immediate years following the abrupt $4 \mathrm{xCO}_{2}$. Put another way, these are regions of delayed warming following a perturbation, presumably because ocean heat transports, because of circulation and mixing, convey heat more efficiently into the interior or to other regions (also see section 7).

In some regions, there are similarities between the change in feedback patterns (Fig. 4, right) and the change in surface warming pattern (Fig. 5c). In particular, the enhanced warming of the east tropical Pacific and Southern Ocean coincides with more positive cloud feedbacks in these regions. However, there are also other regions where large feedback changes occur above relatively unchanged warming patterns, such as the Indian Ocean at around $30^{\circ} \mathrm{S}$ and the Atlantic Ocean at around $30^{\circ} \mathrm{N}$. Presumably, there are nonlocal connections between the warming pattern and feedbacks via the atmospheric circulation or local nonlinearities, and a purely local framework (e.g., Armour et al. 2013) cannot give an entirely adequate explanation. There would be value in future work examining the extent to which time-varying regional feedback processes in AOGCMs should be considered local or not.

\section{Dependence of feedbacks on an evolving pattern of surface warming}

To test the hypothesis that the change in SST patterns identified in section 3 are responsible for the change in feedback parameters shown in section 2, in this section we perform a series of atmosphere-only (AGCM) experiments. These experiments are introduced in turn in the following subsections, and summarized for reference in Table 2.

\section{a. Climate change under $4 x \mathrm{CO}_{2}$ with an evolving pattern of SST change}

We force the atmospheric components of HadCM3 and HadGEM2 (HadCM3-A and HadGEM2-A, respectively) with $\mathrm{CO}_{2}$ and monthly-mean SST and sea ice fraction derived from their respective coupled AOGCM piControl and abrupt $4 \mathrm{xCO}_{2}$ simulations. We thus aim to reproduce the surface and atmospheric climate change simulation of each AOGCM (HadCM3 and HadGEM2ES) with its respective AGCM (HadCM3-A and HadGEM2-A). The HadCM3-A and HadGEM2-A experiments use standard AMIP-type techniques (i.e., the model linearly interpolates between monthly-mean values to obtain submonthly boundary conditions). The absence of high-frequency surface variability and suppression of atmosphere-ocean feedback means that the AGCM control climate differs slightly from that of the AOGCM, so we cannot use the latter's piControl as a control for the AGCM abrupt $4 \mathrm{xCO}_{2}$. In this and following subsections, our results for climate change simulated by each AGCM are calculated as differences from its own control.

For HadGEM2 we have a single realization of the abrupt $4 \mathrm{xCO}_{2}$ AOGCM experiment, and we carry out one HadGEM2-A experiment with monthly-mean piControl boundary conditions and one with abrupt $4 \mathrm{xCO}_{2}$ boundary conditions, both of $150 \mathrm{yr}$. For HadCM3-A we reduce the noise of unforced variability by (i) building boundary conditions from the ensemble mean of the seven coupled atmosphere-ocean $\mathrm{HadCM} 3$ abrupt $4 \mathrm{xCO}_{2}$ simulations and then (ii) performing an ensemble of seven abrupt $4 \mathrm{xCO}_{2}$ HadCM3-A runs. The HadCM3-A piControl is a single realization using climatological rather than a time series of monthly-mean boundary conditions derived from the HadCM3 piControl. Using climatological monthly means instead of individual months reduces the interannual variability, which makes it more consistent with the ensemble-mean boundary conditions derived from the abrupt $4 \mathrm{xCO}_{2}$ experiments. Because of the expense of running ensembles, the HadCM3-A experiments are $100 \mathrm{yr}$ long. The AGCM experiment with abrupt $4 \mathrm{xCO}_{2}$ boundary conditions is named "E4" in Table 1 (for "evolving" pattern of SST change and " $4 \mathrm{xCO}_{2}$ ").

Figures 6a,b compares the Gregory plots of the HadCM3-A and HadCM3 results (black points against gray points). HadCM3-A reproduces the time-varying net feedback parameter simulated by the AOGCM: that is, the net feedback parameter becomes more positive with 
TABLE 2. List of AGCM experiments. "Both" in the model column means that the experiment was carried out with both HadGEM2-A and HadCM3-A AGCMs. The $\mathrm{CO}_{2}$ column gives the atmospheric $\mathrm{CO}_{2}$ concentration in the AGCM experiment relative to the control. "Evolving" sea surface boundary conditions means that monthly-mean SSTs were used from the $4 \mathrm{xCO}_{2}$ AOGCM experiment, "scaled final" pattern means that the climatological time-mean SST change of the final $20 \mathrm{yr}$ of the AOGCM experiment was scaled by globalmean temperature change and added onto the control SSTs, "scaled initial" pattern means the same procedure using the initial $20 \mathrm{yr}$ of the AOGCM experiment, and "scaled tangent" pattern used the derivative of local SST with respect to global-mean temperature for years 21-100 (more details are given in the text). The $n$ column indicates the number of members in the ensembles of HadCM3-A experiments having time-dependent boundary conditions. In all cases, the sea ice fraction boundary conditions use the evolving monthly-mean sea ice fractions from the $4 \mathrm{xCO}_{2} \mathrm{AOGCM}$ experiment (deviations from this are indicated in text where applicable).

\begin{tabular}{|c|c|c|c|c|}
\hline Name & Model & $\mathrm{CO}_{2}$ & $n$ & Sea surface boundary conditions \\
\hline E4 & Both & $4 \mathrm{xCO}_{2}$ & 7 & Evolving pattern: monthly SSTs from $4 \mathrm{xCO}_{2}$ AOGCM output \\
\hline E1 & Both & $1 \mathrm{xCO}_{2}$ & 4 & \\
\hline SF4 & Both & $4 \mathrm{xCO}_{2}$ & 4 & Scaled final pattern: climatology of SST change based on the final $20 \mathrm{yr}$ \\
\hline SF1 & HadGEM2-A & $1 \mathrm{xCO}_{2}$ & - & $\begin{array}{l}\text { of } 4 \mathrm{xCO}_{2} \mathrm{AOGCM} \text {, scaled by monthly global } \Delta T \text { time series and } \\
\text { added to control SSTs }\end{array}$ \\
\hline SI4 & HadCM3-A & $4 \mathrm{xCO}_{2}$ & 4 & Scaled initial pattern: climatology of SST change based on the initial \\
\hline SI1 & HadCM3-A & $1 \mathrm{xCO}_{2}$ & 4 & $\begin{array}{l}20 \mathrm{yr} \text { of } 4 \mathrm{xCO}_{2} \mathrm{AOGCM} \text {, scaled by monthly global } \Delta T \text { time series } \\
\text { and added to control SSTs }\end{array}$ \\
\hline ST4 & HadCM3-A & $4 \mathrm{xCO}_{2}$ & 4 & $\begin{array}{l}\text { Scaled tangent pattern: climatology of SST change based on the de- } \\
\text { rivative of local SST with respect to global } \Delta T \text { for years } 21-100 \text { of } \\
4 \mathrm{xCO}_{2} \text { AOGCM, scaled by monthly global } \Delta T \text { time series and added } \\
\text { to control SSTs }\end{array}$ \\
\hline $\mathrm{CC} 4$ & HadCM3-A & $4 \mathrm{xCO}_{2}$ & - & $\begin{array}{l}\text { Constant control pattern: SST climatology based on AOGCM } \\
\text { piControl SSTs }\end{array}$ \\
\hline CI4 & HadCM3-A & $4 \mathrm{xCO}_{2}$ & - & $\begin{array}{l}\text { Constant initial pattern: SST climatology based on initial } 20 \mathrm{yr} \text { of } \\
4 \mathrm{xCO}_{2} \mathrm{AOGCM}\end{array}$ \\
\hline $\mathrm{CF} 4$ & HadCM3-A & $4 \mathrm{xCO}_{2}$ & - & $\begin{array}{l}\text { Constant final pattern: SST climatology based on final } 20 \mathrm{yr} \text { of } 4 \mathrm{xCO}_{2} \\
\text { AOGCM }\end{array}$ \\
\hline $\mathrm{CZ1}$ & HadCM3-A & $1 \mathrm{xCO}_{2}$ & - & $\begin{array}{l}\text { Constant pattern derived from regressing the } 4 \mathrm{xCO}_{2} \text { AOGCM local } \\
\text { SST against global } \Delta T \text { for years } 1-20 \text { and extrapolating to monthly } \\
\text { global } \Delta T=0\end{array}$ \\
\hline
\end{tabular}

time (Fig. 6a) and this is mostly due to an increase in the SW CRE feedback parameter as in the AOGCM (Fig. 6b).

The same is true for the HadGEM2-A (Figs. 6c,d). We perform an additional HadGEM2-A experiment (Figs. 6e,f) where we prescribe the vegetation cover by switching off the dynamic vegetation model. This is because in HadGEM2 there is a coupling between dust aerosol sources and bare soil fraction, simulated by the dynamic vegetation model, which provide strong feedbacks in climate change simulations (Andrews et al. 2012b). This can be seen by contrasting the HadGEM2-A results with fixed vegetation to the HadGEM2-ES results, which shows that the AGCM takes a different path to the AOGCM (Fig. 6e) because of large differences in the response of SW clear-sky fluxes (Fig. 6f), consistent with changes in surface albedo and atmospheric dust aerosol loads that will influence reflected $\mathrm{SW}$ radiation. This response appears to be nonlinear with $\Delta T$, since the AGCM and AOGCM separate within the first few years and then evolve in parallel. While this clearly contributes to the nonlinear behavior in this particular model, we do not believe it to be the basic physical driver of the nonlinear $N$ versus $\Delta T$ relationship, which occurs in many models that are not considered "earth system" models. Hence, in the rest of this study we prescribe the vegetation in our AGCM design to focus on the basic physical drivers.

\section{b. Climate change under $4 x \mathrm{CO}_{2}$ with fixed patterns of SST change}

Having shown that HadCM3-A and HadGEM2-A forced with monthly-mean output from their AOGCM counterpart are able to reproduce the nonlinear dependence of $N$ and cloud feedback on $\Delta T$ (section 4a), we next use the atmosphere GCM design to test the hypothesis that the nonlinearity arises from the evolution of the SST patterns. We do this by repeating the HadCM3-A and HadGEM2-A experiments, but this time we prevent the SST warming pattern from changing. We build a monthly-mean climatological pattern of SST change (local $\Delta T$ normalized by global $\Delta T$ ) representative of the last $20 \mathrm{yr}$ of the abrupt $4 \mathrm{xCO}_{2}$ simulation, scale this warming pattern by the global-mean monthly $\Delta T$ time series and add it to the piControl monthly SST fields. Using these SST boundary conditions, the atmosphere GCMs are forced to take the same global-mean monthly $\Delta T$ path as the AOGCM abrupt $4 \mathrm{xCO}_{2}$ results but with a fixed pattern of SST 
(a) HadCM3 compared to HadCM3-A

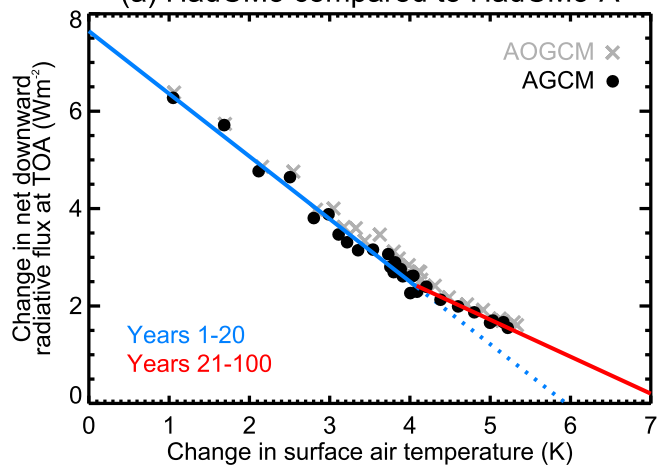

(c) HadGEM2-ES compared to HadGEM2-A

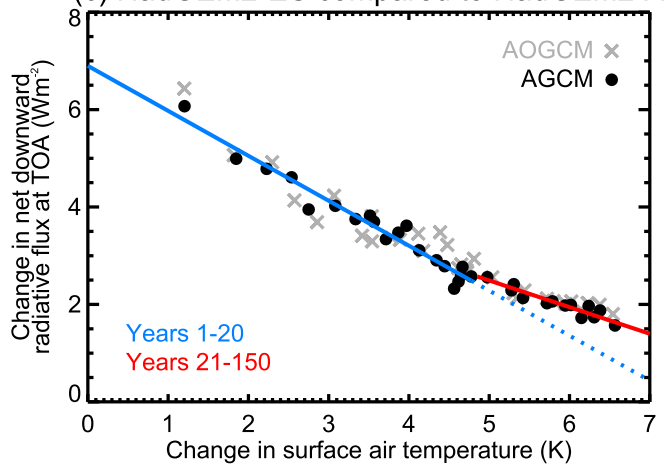

(e) HadGEM2-ES compared to HadGEM2-A



(b) Radiative components of (a)

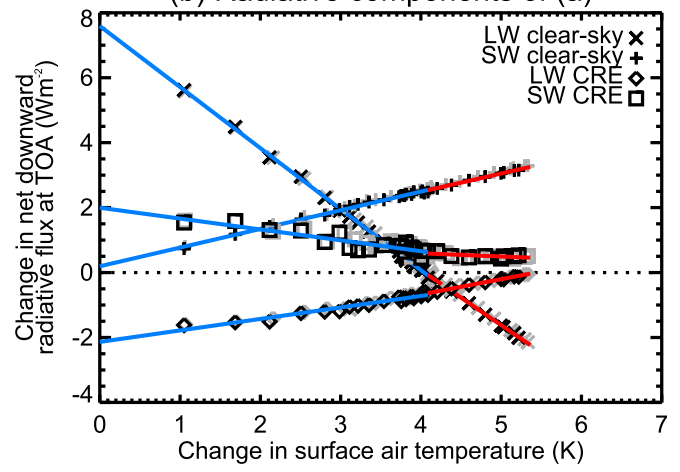

(d) Radiative components of (c)

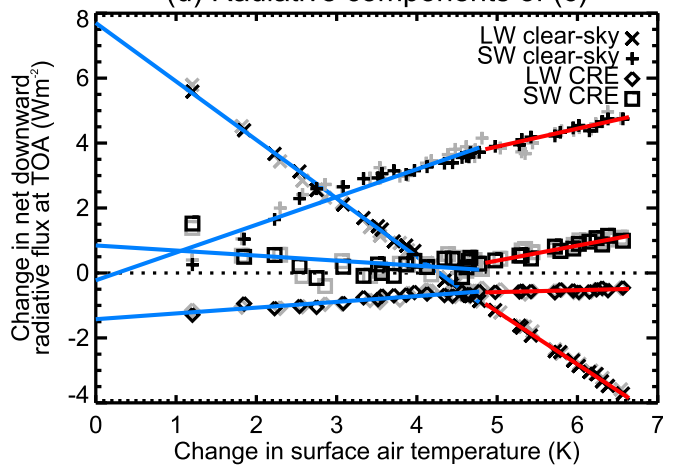

(f) Radiative components of $(e)$

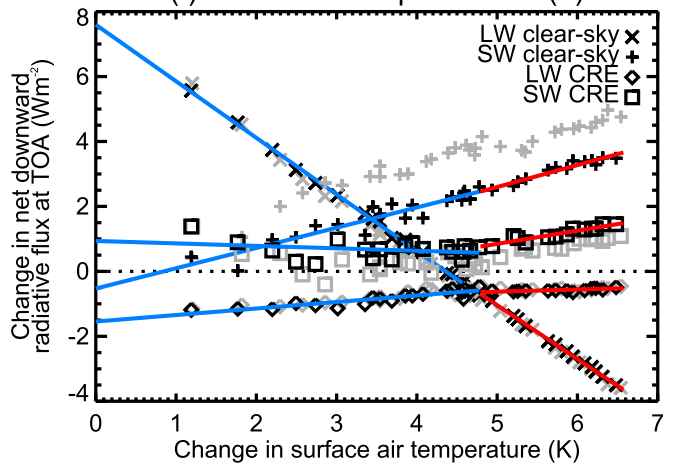

FIG. 6. (a)The HadCM3 AOGCM Gregory plot for abrupt4 $\mathrm{xCO}_{2}$ (gray points) compared to a HadCM3-A AGCM experiment (black points) forced with $\mathrm{CO}_{2}$ and monthly-mean SSTs and sea ice fractions as simulated by the AOGCM (experiment E4 in Table 2); and (b) the radiative components of (a). (c),(d) As in (a),(b), but for a HadGEM2-ES AOGCM and HadGEM2-A AGCM experiment. (e),(f) As in (a),(b), but for a HadGEM2-A AGCM experiment that excludes the dynamic vegetation model. The HadCM3-A AGCM results are ensemble means from seven-member ensembles, while the HadGEM2-A AGCM results are single realizations. Lines show regression fits to the global annual-mean data points for years 1-20 (blue) and subsequent years (red). The plots show global annual-mean data for the first $20 \mathrm{yr}$, followed by decadal means. The blue dotted lines in (a),(c),(e) represent the path the model would have taken to equilibrium if it had maintained the feedback strengths as simulated during the early years of the experiment.

change. This experiment is labeled "SF4" in Table 1 (for "scaled final pattern" of SST change under $4 \mathrm{xCO}_{2}$ ). With HadCM3-A, SF4 and other time-dependent experiments described later in this section are each an ensemble of four integrations from different initial states, and we show the ensemble mean.
With the scaled final pattern (experiment SF4) the net radiative response is largely linear with $\Delta T$ in both models (Figs. 7a,c). Similarly, the component responses (Figs. 7b,d) are also linear with $\Delta T$, in contrast to the results with the evolving SST pattern (E4) which showed SW CRE feedback to become more positive with time. Since most 
(a) HadCM3-A fixed pattern of SST change

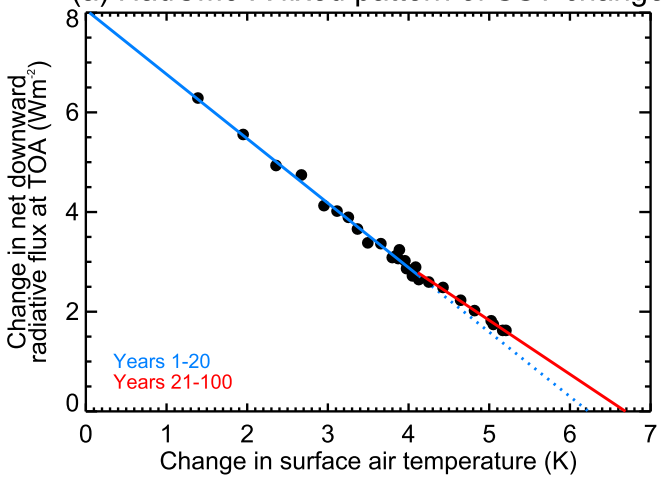

(c) HadGEM2-A fixed pattern of SST change

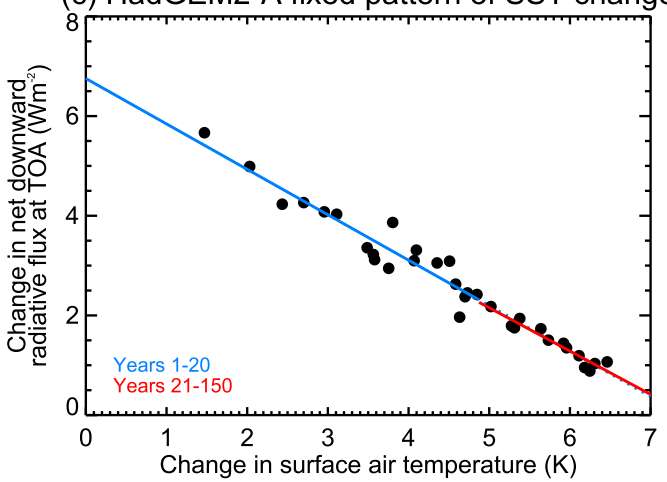

(b) Radiative components of (a)



(d) Radiative components (c)

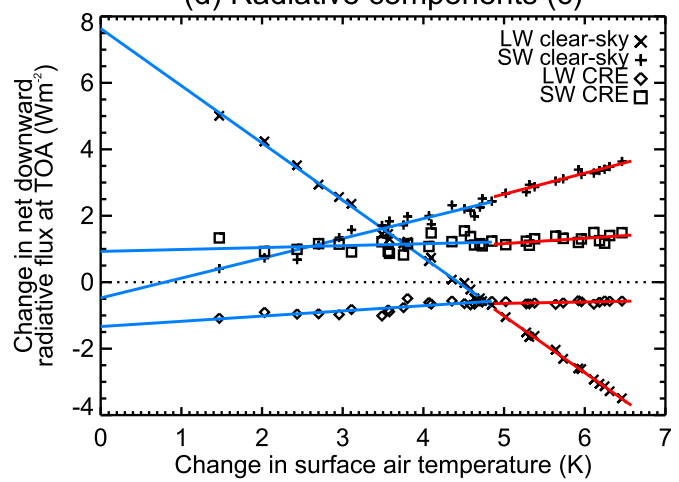

FIG. 7. The $4 \mathrm{xCO}_{2}$ Gregory plots for (a),(c) HadCM3-A and HadGEM2-A AGCMs forced with $\mathrm{CO}_{2}$ and sea ice fractions as simulated by the corresponding AOGCM but with fixed patterns of SST change (experiment SF4 in Table 2), respectively; and (b),(d) the radiative components of (a),(c), respectively. The monthly-mean SST patterns are derived from the last $20 \mathrm{yr}$ of the AOGCM experiment and then scaled by the monthly-mean global $\Delta T$ time series of the AOGCM. The AGCM therefore takes the same global $\Delta T$ path as the $4 \mathrm{xCO}_{2}$ AOGCM model but with a fixed pattern of SST change. Lines show OLS regression fits to the global annual-mean data points for years 1-20 (blue) and subsequent years (red). The plots show global annual-mean data for the first $20 \mathrm{yr}$, followed by decadal means. The blue dotted line in (a) represents the path the model would have taken to equilibrium if it had maintained the feedback strengths as simulated during the early years of the experiment; in (c), the red line overlies the blue dotted line.

of the nonlinear behavior has been removed when the SST patterns are forced to take a fixed path, we identify the evolving pattern of surface warming as the main driver of the nonlinear radiative response with $\Delta T$. The remaining deviations of SF4 from a perfectly straight line in HadCM3-A are further discussed in section 4c.

Using HadCM3-A (but not HadGEM2-A because of its computational expense), we have carried out various additional experiments (listed in Table 2), which we describe in the remainder of this section. These experiments allow us to demonstrate that the trajectory of the HadCM3 abrupt $4 \mathrm{xCO}_{2}$ experiment in $(\Delta T, N)$ space, particularly its declining (more positive) climate feedback parameter as time passes, can be mostly replicated by applying the different patterns of SST change that prevail as the evolution proceeds. Thus, they provide further evidence that the relationship between $N$ and $\Delta T$ is determined by the SST pattern.
We carry out three experiments with $4 \mathrm{xCO}_{2}$ using constant climatological sea surface boundary conditions. Experiment CC4 (for "constant control pattern" under $4 \mathrm{xCO}_{2}, 100 \mathrm{yr}$ long) uses the monthly control climatology; this experiment is the same as the HadCM3-A control, except for the $\mathrm{CO}_{2}$ concentration, and is the design proposed by Hansen et al. (2005) to estimate the effective radiative forcing [i.e., imposing $\Delta T=0$ implies $F=N$ from Eq. (1)]. We note, however, that CC4 does not lie exactly at $\Delta T=0 \mathrm{~K}$, because of land surface warming, and hence its $N$ is a biased estimate of the effective radiative forcing (Hansen et al. 2005; Andrews et al. 2012a).

Experiments CI4 (for “constant initial pattern," $80 \mathrm{yr}$ long) and CF4 (for "constant final pattern," $100 \mathrm{yr}$ long) use monthly climatologies made from years 1-20 and years $81-100$, respectively, of the abrupt $4 \mathrm{xCO}_{2}$ AOGCM experiment. These experiments are constructed to be 
(a)

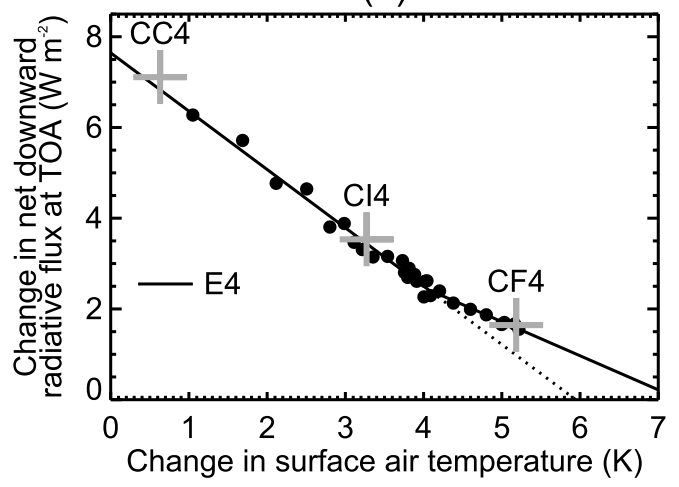

(c)

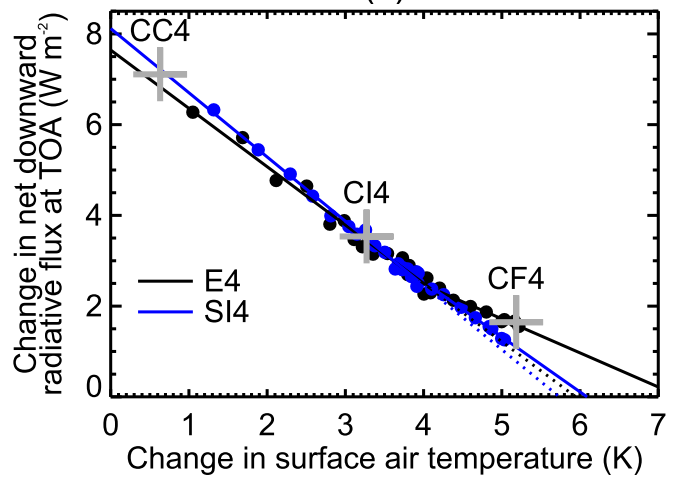

(b)

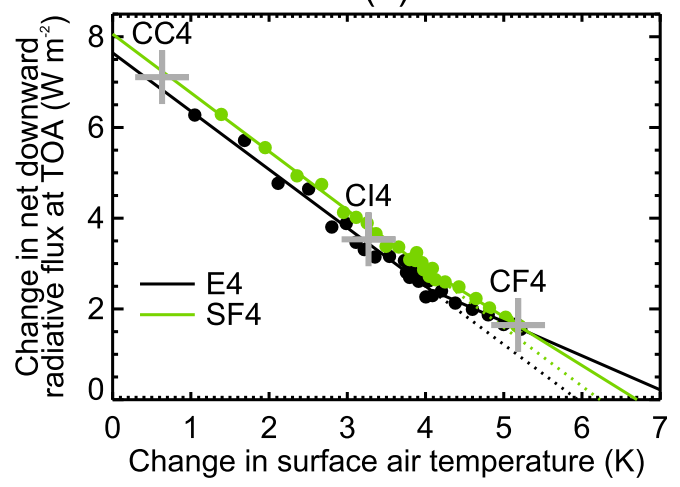

(d)

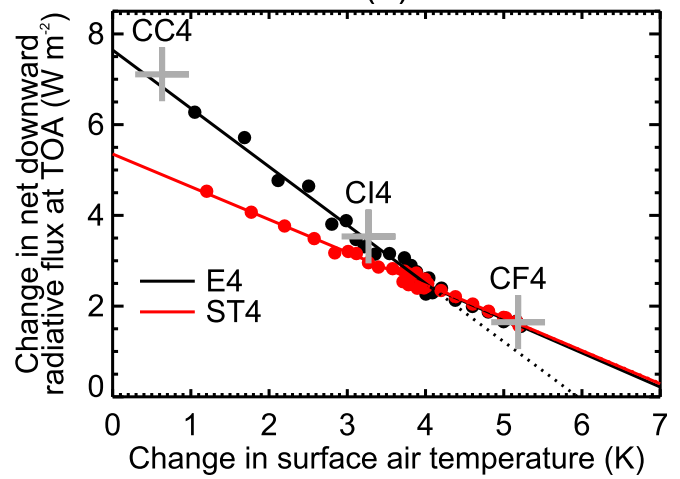

FIG. 8. The HadCM3-A experiment E4, which reproduces the $\mathrm{AOGCM} 4 \mathrm{xCO}_{2}$ results, and its relationship to (a) the constant climate experiments $\mathrm{CC} 4\left(4 \mathrm{xCO}_{2}\right.$ with climatological control SSTs), $\mathrm{CI} 4\left(4 \mathrm{xCO}_{2}\right.$ with climatological SSTs based on the initial $20 \mathrm{yr}$ of abrupt $\left.4 \mathrm{xCO}_{2}\right)$, and $\mathrm{CF} 4\left(4 \mathrm{xCO}_{2}\right.$ with climatological SSTs based on the final $20 \mathrm{yr}$ of abrupt $\left.4 \mathrm{xCO}_{2}\right)$; (b) SF4 ( $4 \mathrm{xCO}_{2}$ with climatological SSTs based on the final $20 \mathrm{yr}$ of abrupt $4 \mathrm{xCO}_{2}$, then scaled by the global monthly-mean $\Delta T$ time series); (c) SI4 (4xCO 2 with climatological SSTs based on the initial $20 \mathrm{yr}$ of abrupt $4 \mathrm{xCO}_{2}$, then scaled by the global monthly-mean $\Delta T$ time series); and (d) ST4 (4xCO $\mathrm{x}_{2}$ with climatological SSTs based on the derivative of local SST change with respect to global $\Delta T$ over years $20-100$ of abrupt $4 \mathrm{xCO}_{2}$, then scaled by the global monthly-mean $\Delta \mathrm{T}$ time series). The linear fits are separated at year 20 , and the dotted lines represent the path the model would have taken to equilibrium if it had maintained the feedback strengths as simulated during the early years of the experiment.

time slices of climate states that occur during the abrupt $4 \mathrm{xCO}_{2}$ AOGCM experiment, and their results lie on the $(\Delta T, N)$ curve (Fig. 8a). These time-slice experiments confirm that the radiation balance and climate feedbacks are determined by the prevailing sea surface conditions, with no other significant dependence on the time evolution simulated by the AOGCM.

By construction, the SSTs used in the last $20 \mathrm{yr}$ of the scaled final pattern (SF4) have a climatological time mean that is approximately equal to the constant climatology applied in $\mathrm{CF} 4$, which was computed from the same $20 \mathrm{yr}$ of $\mathrm{HadCM} 3$ abrupt $4 \mathrm{xCO}_{2}$. Consequently, SF4 ends at the state simulated by CF4, as does E4 (Fig. 8b). Because most of the nonlinearity of E4 is removed by using fixed patterns, SF4 clearly bypasses the state of CI4 on its way to CF4 (Fig. 8b). We note that the forcing implied by the $N$ intercept of SF4 is about $0.5 \mathrm{~W} \mathrm{~m}^{-2}$ more than for E4; this is discussed in section 5 .

In experiment SI4 (for "scaled initial pattern" of SST change under $4 \mathrm{xCO}_{2}$ ) we force HadCM3-A with SSTs using the pattern of the time mean of the initial $20 \mathrm{yr}$ of HadCM3 abrupt $4 \mathrm{xCO}_{2}$, scaled by $\Delta T$. This experiment consequently follows the $(\Delta T, N)$ trajectory of $\mathrm{E} 4$ for its first $20 \mathrm{yr}$, passing through the state of CI4 but then continues along the same straight line, from which the experiment with evolving SST patterns (E4) diverges with a concave-upward curve (Fig. 8c).

In experiment ST4 (for "scaled tangent pattern" of SST change, under $4 \mathrm{xCO}_{2}$ ), we force HadCM3-A with SST fields $C(\mathbf{x}, m)+\Delta T_{s}(m, t) D(\mathbf{x}, m)$, where $\Delta T_{s}$ is surface temperature change, $\mathbf{x}$ is geographical location, $m$ is the month, $t$ is the year, $C$ is the intercept, and $D$ is the slope obtained by linear regression of the 


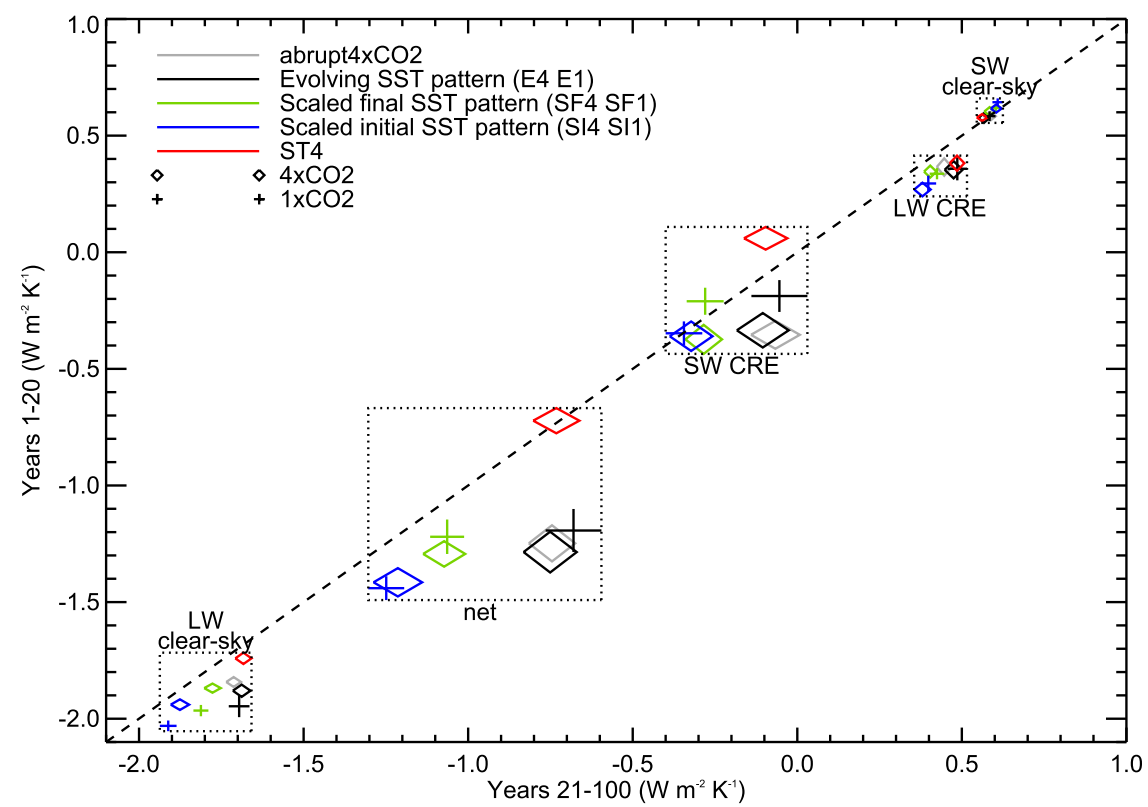

FIG. 9. Comparison of the net feedback parameter $(\alpha)$ and its various components as diagnosed from the early (years 1-20) and subsequent (years 21-100) years of the various HadCM3 AGCM experiments. The sizes of the symbol represent the $95 \%$ confidence interval, as determined from the standard deviation in the regression multiplied by 1.96. Points that fall below the 1:1 line demonstrate a significant shallowing of the slope (i.e., the feedback parameter becomes less negative) as time passes.

abrupt $4 \mathrm{xCO}_{2} \operatorname{SST}(\mathbf{x}, m, t)$ against global-mean monthlymean surface temperature change $\Delta T_{s}(m, t)$, for years 21-100. The term $D$ is the derivative of local SST change with respect to global $\Delta T$ experienced after the first $20 \mathrm{yr}$, the equivalent of Fig. $5 \mathrm{~b}$ for the CMIP5 ensemble. The purpose of this experiment is to test whether we can simulate the tangent to the curve given the appropriate pattern of SST change. We find, as expected, that experiment ST4 has the same slope, or "differential climate feedback parameter" (Gregory et al. 2004), as the experiment with evolving SST patterns (E4) after the initial 20 yr (Fig. 8d).

\section{c. Dependence of climate feedback on SST pattern, $\Delta T$, and $\mathrm{CO}_{2}$}

We can gain a detailed view of the dependence of radiative feedbacks on SST patterns and $\Delta T$ by comparing the feedback parameters for years 1-20 and years 21 onward in all our experiments (Fig. 9 for HadCM3; HadGEM2 results not shown). In this comparison, we also test for any dependence on $\mathrm{CO}_{2}$ concentration by including further atmosphere GCM experiments. Experiment E1 (for "evolving pattern" of SST change, under $1 \mathrm{xCO}_{2}$, with both HadCM3-A and HadGEM2-A) is forced by changing SSTs and sea ice from the abrupt $4 \mathrm{xCO}_{2}$ simulation, exactly as in the corresponding evolving SST experiment E4 but with the control $\mathrm{CO}_{2}$ concentration $\left(1 \mathrm{xCO}_{2}\right)$ (Table 2). Similarly, experiments SF1 and SI1 (HadCM3-A only) use scaled final and initial SST patterns, exactly as in the corresponding experiments SF4 and SI4 of section $4 \mathrm{~b}$ but with $1 \mathrm{xCO}_{2}$. Thus, climate change is forced in E1, SF1, and SI1 by the imposed SST and sea ice change but not by $\mathrm{CO}_{2}$ change. The HadCM3-A experiments are each an ensemble of four integrations from different initial states, and we show the ensemble mean.

As in the CMIP5 ensemble, there is a small but significant weakening of the LW clear-sky feedback: that is, it becomes less negative as $\Delta T$ increases, in both models. This occurs for all the SST patterns, both fixed and evolving. In both models, LW clear-sky feedback in years 1-20 shows a small but significant dependence on $\mathrm{CO}_{2}$, being about $0.1 \mathrm{~W} \mathrm{~m}^{-2} \mathrm{~K}^{-1}$ less negative for $4 \mathrm{xCO}_{2}$. The LW clear-sky feedback depends also on the SST pattern in HadCM3-A, and this dependence further contributes to the nonlinearity of abrupt $4 \mathrm{xCO}_{2}$. A small additional nonlinearity arises from LW CRE feedback in HadCM3. In both models, SW clear-sky feedback shows hardly any dependence on SST pattern, $\Delta T$ or $\mathrm{CO}_{2}$.

As we have already found, the nonlinearity of the net feedback in the abrupt $4 \mathrm{xCO}_{2}$ AOGCM experiment (deviation of from the 1:1 line in Fig. 9) arises primarily from the SW CRE feedback. Enforcing a fixed pattern of warming largely eliminates this source of nonlinearity. 
The HadGEM2-A experiment with evolving SST patterns under $1 \mathrm{xCO}_{2}(\mathrm{E} 1)$ has a SW CRE feedback in both time periods, which is statistically indistinguishable from the same experiment under $4 \mathrm{xCO}_{2}(\mathrm{E} 4)$. With HadCM3-A, the SW CRE feedback parameter intersects the 1:1 line for nearly all the fixed-pattern experiments except ST4 (Fig. 9), but it appears that SW CRE feedback with a given pattern of SST change can depend also on $\mathrm{CO}_{2}$ (comparing E1 with E4 and SF1 with SF4).

We have advanced the hypothesis that the pattern of SST change largely determines the SW CRE feedback. We note that in HadCM3-A the SW CRE feedback of SI4 agrees with E4 in years 1-20 and ST4 agrees with E4 in years 81-100 (Fig. 9), consistent with our hypothesis and with the reproduction of portions of the E4 trajectory by SI4 and ST4 (Figs. 8c,d). It could seem surprising, therefore, that SF4 is statistically indistinguishable from SI4 in SW CRE feedback (Fig. 9), despite their different patterns of SST change. This is because the majority of the global warming during E4 occurs during the first $20 \mathrm{yr}$ and hence with the pattern of SI4 (Fig. 8). Although the trajectory of E4 during years 21-100 has the markedly different SST pattern of ST4, relatively little additional warming occurs with this pattern. Thus, the scaled pattern and the SW CRE feedback parameter of SF4 are much more similar to SI4 than to ST4.

\section{Definition of radiative forcing}

The linear regression method used in the previous sections to diagnose the radiative feedbacks also allows us to diagnose the effective radiative forcing (ERF) from the $N$ intercept (Gregory et al. 2004). This section uses the large number of HadCM3-A experiments to better understand how the $4 \mathrm{xCO}_{2}$ effective radiative forcing arises in this model. Specifically, in keeping with the previous sections that showed there was a strong dependence of radiative feedbacks on the evolution of the SST patterns, we are interested in a small but significant effect of rapid SST pattern adjustments (see below) on the ERF.

We estimate the ERF (Table 3) in each of our HadCM3-A experiments with time-dependent boundary conditions as the $N$ intercept of the regression line for years 1-20 (Gregory et al. 2004). Focusing only on the early years allows us to extrapolate back to $\Delta T=$ 0 without the result being influenced by the curvature discussed in the previous sections that arises on the longer time scales and would act to reduce the ERF. The uncertainty of the intercept arises from the scatter of the points around the regression line. We use $t$ tests for statistical differences at the $5 \%$ significance level between the ERFs from pairs of experiments. The ERF of
TABLE 3. The effective radiative forcing $F$ for $4 \mathrm{xCO}_{2}$ in $\mathrm{W} \mathrm{m}^{-2}$, for various HadCM3 experiments, all except the first using the AGCM. The $F$ is determined from the $N$ intercept of the Gregory plot based on a linear fit to years 1-20, except for CC4, CC4adj, and CZ1 (see text). Errors represent the 95\% confidence interval.

\begin{tabular}{lr}
\hline \hline Experiment & $F\left(\mathrm{~W} \mathrm{~m}^{-2}\right)$ \\
\hline AOGCM & $7.73 \pm 0.26$ \\
E4 & $7.64 \pm 0.30$ \\
CC4 & $7.11 \pm 0.04$ \\
CC4adj & $7.92 \pm 0.07$ \\
SF4 & $8.06 \pm 0.19$ \\
SI4 & $8.12 \pm 0.20$ \\
SI4 & $8.21 \pm 0.18$ \\
E1 & $-0.47 \pm 0.26$ \\
SF1 & $0.07 \pm 0.21$ \\
SI1 & $0.19 \pm 0.14$ \\
E4 - E1 & $8.11 \pm 0.39$ \\
SF4 - SF1 & $7.98 \pm 0.29$ \\
SI4 - SI1 & $7.93 \pm 0.25$ \\
E4 - SF4 & $-0.41 \pm 0.35$ \\
E4 - SI4 & $-0.47 \pm 0.36$ \\
CZ1 & $-0.53 \pm 0.05$ \\
\hline
\end{tabular}

$7.6 \pm 0.3 \mathrm{~W} \mathrm{~m}^{-2}$ from $\mathrm{E} 4$ is consistent with the ERF of the abrupt $4 \mathrm{xCO}_{2} \mathrm{AOGCM}$ HadCM3 experiment that it emulates (Table 3).

As noted in section $4 \mathrm{~b}$ (Fig. 8), the Hansen or fixedSST estimate of the $4 \mathrm{xCO}_{2}$ ERF from $N$ in $\mathrm{CC} 4$ is significantly less than the E4 ERF that is determined from regressing $N$ back to $\Delta T=0$, because preventing SST change in the fixed-SST experiment does not prevent land surface temperature change. This result is common amongst CMIP5 models (Andrews et al. 2012a). (Note the $\mathrm{CC} 4$ forcing estimate has a much smaller uncertainty than the other forcings because it is computed from $100 \mathrm{yr}$ of a steady state.) As proposed by Hansen et al. (2005), we adjust this forcing back to $\Delta T=0$ using the net climate feedback parameter of E4, allowing also for the uncertainty of the latter, and thus obtain a $4 \mathrm{xCO}_{2}$ ERF that is not significantly different from E4. However, as noted by Gregory and Webb (2008), this assumption is physically implausible because it assumes the feedbacks in the transient experiment (where both the land and SSTs respond) are the same in the fixedSST experiments (where the feedbacks over the ocean have been inhibited by the experimental design as far as possible).

The ERFs from the scaled final and initial patterns of SST change (SF4 and SI4) are statistically indistinguishable but significantly greater than from E4 (one-tailed $t$ test). (The ERF of SI4I, in which sea ice changes as well as SST changes are scaled with $\Delta T$, is not distinguishable from SI4.) Since the $\mathrm{CO}_{2}$ concentration is the same in all these experiments, the difference can come only from the SSTs. In the experiments with scaled 
SSTs, the extrapolation to global-mean $\Delta T=0$ is also by construction an extrapolation of local SST everywhere back to zero. In E4, however, the extrapolation to $\Delta T=0$ does not enforce zero local SST change.

A possible explanation of this difference is that in response to abrupt imposition of $4 \mathrm{xCO}_{2}$ there is a rapid SST adjustment with zero global-mean SST change but local positive and negative SST changes, which induce a nonzero change in global-mean TOA radiative balance. Thus, in E4 there is a rapid negative forcing adjustment due to SST adjustment, which is excluded in the scaled-SST experiments and is not the same as the land temperature adjustment that occurs in all the $4 \mathrm{xCO}_{2}$ experiments. This interpretation is corroborated by the AGCM experiments with $1 \mathrm{xCO}_{2}$. E1 (evolving SST patterns under $1 \mathrm{xCO}_{2}$ ) has an ERF of about $-0.5 \mathrm{~W} \mathrm{~m}^{-2}$, which we attribute to SST adjustment, since a forcing is being diagnosed without any change in $\mathrm{CO}_{2}$, while the scaled-SST experiments under $1 \mathrm{xCO}_{2}$ have ERFs much closer to zero. We can alternatively estimate the effect of SST adjustment by considering the difference in ERF between $\mathrm{E} 4$ and the $4 \mathrm{xCO}_{2}$ scaledSST experiments, which differ only in respect of the SSTs (Table 3). These estimates agree with the ERF of E1. The mean of these estimates of the effect of SST adjustment on ERF is $-0.5 \pm 0.2 \mathrm{~W} \mathrm{~m}^{-2}$.

We can also construct this state, using a similar method to the one we employed for the scaled tangent experiment (ST4; section 4b). We regress the monthly-mean SST(x, $m, t)$ for years 1-20 from the abrupt $4 \mathrm{xCO}_{2}$ experiment against global-mean monthly-mean surface temperature $\Delta T_{s}(m, t)$ change in those years from experiment E1, which was forced by the abrupt $4 \mathrm{xCO}_{2} \mathrm{SST}$. The intercept of this regression gives us an estimated $\operatorname{SSTclim}(\mathbf{x}, m)$ field consistent with $\Delta T_{s}(m, t)=0$ for each month $m$. We carry out experiment CZ1 (100 yr long) with this monthly SST climatology and with sea ice and $\mathrm{CO}_{2}$ for the control climate. The field of annual-mean surface air temperature anomaly has a global mean of $\Delta T=-0.036 \pm 0.009 \mathrm{~K}$, very near to zero, but an area-weighted spatial standard deviation of $0.5 \mathrm{~K}$, and it shows warming of over $1 \mathrm{~K}$ around $30^{\circ} \mathrm{S}$ and $45^{\circ} \mathrm{N}$, with cooling of comparable magnitude at lower and higher latitudes (Fig. 10). The globalmean annual-mean $N=-0.53 \pm 0.05 \mathrm{~W} \mathrm{~m}^{-2}$, substantially different from zero (95\% confidence intervals, assuming annual variations to be independent). This estimate of the forcing adjustment due to rapid SST adjustment in response to $4 \mathrm{xCO}_{2}$ is more precise than and consistent with the estimate made above from time-dependent experiments. Experiment CZ1 demonstrates that a nonzero perturbation to the global energy budget can be produced by a zero global-mean temperature change, because of regionally varying SSTs and feedbacks.

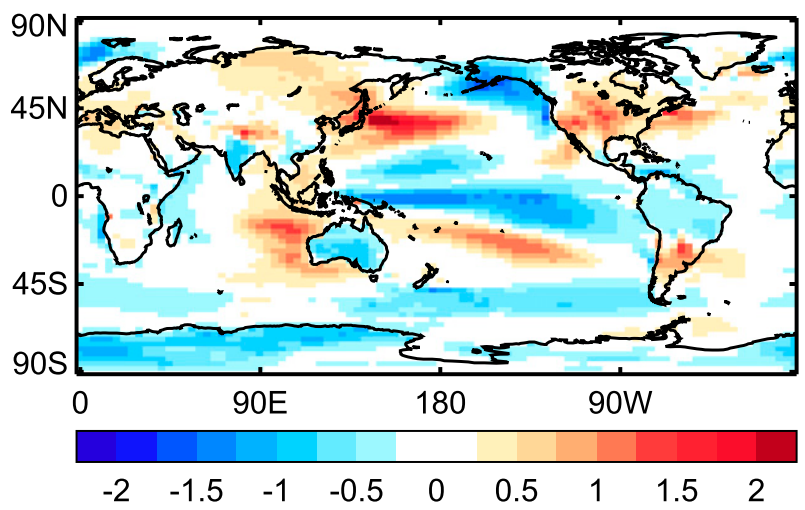

FIG. 10. Change in surface air temperature with zero global mean in response to abrupt $4 \mathrm{xCO}_{2}$ rapid SST adjustment in HadCM3.

The state following SST adjustment and with $\Delta T=$ 0 does not actually occur in the trajectory of the abrupt $4 \mathrm{xCO}_{2}$ AOGCM experiment or E4 in the AGCM. We suppose that the SST adjustment takes place on time scales of less than $1 \mathrm{yr}$, causing a curvature in the Gregory plot that cannot be resolved. However considering this state offers a useful way of quantifying and interpreting the effect within the linear forcingfeedback framework and is consistent with an effective radiative forcing definition that includes adjustments that act on time scales much less than $1 \mathrm{yr}$ (Gregory and Webb 2008). The effect of rapid SST adjustment is included in the forcing estimated by the regression method (requiring zero global-mean temperature change) but excluded by the Hansen method (requiring zero local temperature change), so these two definitions are in principle different but statistically indistinguishable in our experiments (CC4adj and E4 in Table 3).

\section{1000-yr HadGEM2-ES $4 \mathrm{xCO}_{2}$ simulation}

In this section, we make use of an extended HadGEM2-ES AOGCM simulation that has been run for nearly $1300 \mathrm{yr}$ to assess the relationship between $N$ and $\Delta T$ on longer time scales than the $150 \mathrm{yr}$ of CMIP5type simulations previously analyzed. Figure 11a indicates that linearity is a reasonable approximation for the subsequent $1000 \mathrm{yr}$ in this model. However, the linearity may be fortuitous since the decomposition (Fig. 11b) shows a cancellation of terms; on the longer time scale (or greater values of $\Delta T$ reached), the increasing SW CRE feedback is largely offset by a decreasing SW clear-sky feedback (Fig. 11b). Presumably, this is the effect of sea ice or land-snow-cover feedbacks weakening once the system has warmed sufficiently enough to reduce the sea ice and land-snow cover significantly. The timing or temperature dependence of this 
(a) $4 \times \mathrm{XO}_{2}$ HadGEM2-ES

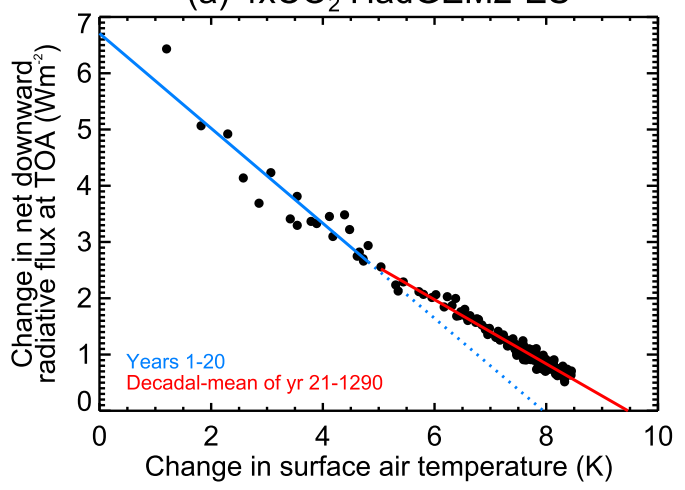

(b) Radiative Components

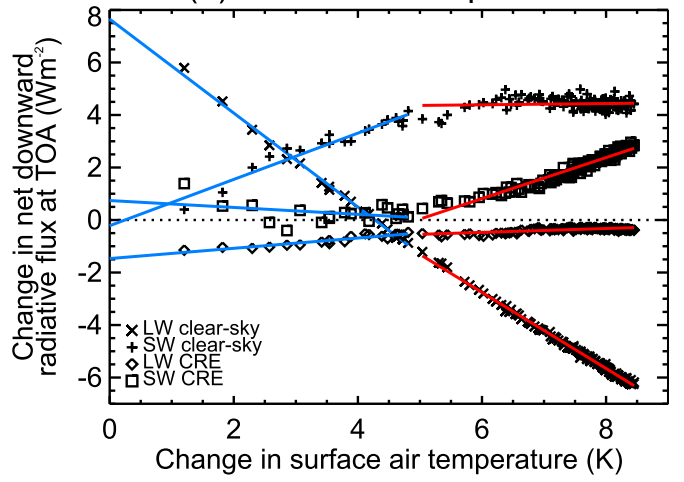

FIG. 11. Gregory plot for (a) the net radiative flux and (b) the radiative component terms for a HadGEM2-ES AOGCM abrupt $4 \mathrm{xCO}_{2}$ simulation run for $1290 \mathrm{yr}$. Lines show linear regression fits to the global annual-mean data points for years 1-20 (blue) and subsequent years (red). The plots show global annual-mean data for the first $20 \mathrm{yr}$, followed by decadal means. The blue dotted line represents the path the AOGCM would have taken to equilibrium if it maintained the feedback strengths as simulated during the early years of the experiment.

effect will likely vary across models, and the degree to which it offsets or introduces new nonlinearities is uncertain.

\section{Summary and discussion}

We have shown that the relationship between the global-mean net heat input $N$ to the climate system (at the top of the atmosphere) and the global-mean surface air temperature change $\Delta T$ is nonlinear in most CMIP5 coupled atmosphere-ocean general circulation models, when forced by an abrupt quadrupling of $\mathrm{CO}_{2}$ levels (see also Andrews et al. 2012a; Geoffroy et al. 2013). The nonlinearity increases the sensitivity of the climate system to external forcing: that is, the feedback parameter becomes less negative and the effective climate sensitivity increases as time passes. Shortwave cloud feedback processes show the largest changes (becoming more positive), although other feedback processes also change.

An important region involved in this effect in the AOGCM mean is the tropical Pacific, although other regions-including the extratropics and in particular the Southern Ocean-also contribute to the increasing (more positive) feedback strengths. In the tropical Pacific, warming is initially delayed in the east for the first few years after the perturbation (see also Held et al. 2010), presumably because of the upwelling of cold unperturbed waters (e.g., Clement et al. 1996; Held et al. 2010). In contrast, on multidecadal time scales the east tropical Pacific warms significantly more than the west and the tropical warming pattern becomes more El Niño like (e.g., Fig. 5; Held et al. 2010). This shift in the tropical Pacific warming pattern appears to have a considerable influence on the evolution of climate feedback in the AOGCMs, particularly cloud feedback (Fig. 4). The mechanisms likely involve complex atmosphere-ocean processes that are not yet well understood in the tropical Pacific on climate change time scales (e.g., Collins et al. 2010). For example, east-west temperature gradients may well be amplified by coupled atmosphere-ocean processes analogous to those acting during the El Niño-Southern Oscillation (ENSO), such as the Bjerknes feedback ( $\mathrm{Ma}$ and Yu 2014). Further work developing a detailed understanding of tropical warming patterns and atmosphere-ocean processes and feedbacks on various time scales in AOGCMs would be useful.

We have devised experiments with the HadCM3 and HadGEM2 AGCMs to test the hypothesis that the change in radiative feedbacks can be explained by an evolving pattern of surface temperature change as simulated in the corresponding AOGCMs. When the AGCMs were forced with a fixed pattern (but with growing amplitude) of warming the radiative feedbacks on global temperature change became linear or nearly so. Thus, we confirm in these AOGCMs that the evolving pattern of surface warming is the dominant cause of nonlinearity.

We have demonstrated using further AGCM experiments that the trajectory of the HadCM3 abrupt $4 \mathrm{xCO}_{2}$ experiment in $(\Delta T, N)$ space, particularly its increasingly positive climate feedback parameter, can be largely explained by the different patterns of SST change that prevail as the evolution proceeds. Rapidly changing SST patterns also modify the effective radiative forcing because of $4 \mathrm{xCO}_{2}$, defined as the perturbation to $N$ caused by the change to $\mathrm{CO}_{2}$, without any global climate change 
having occurred in response (defined by $\Delta T=0$ ). The effective radiative forcing in HadCM3 is reduced by about $6 \%$ by rapid local adjustments (in much less than $1 \mathrm{yr})$ to SST when the $\mathrm{CO}_{2}$ concentration is changed. The pattern of rapid surface temperature change has zero global mean but causes a nonzero perturbation to $N$, which is included in the forcing obtained by the regression (Gregory) method but excluded by definition from the fixed-SST (Hansen) forcing.

The equilibrium climate sensitivity has long been used in climate modeling as a benchmark metric (e.g., Charney et al. 1979). An inconstant feedback parameter in AOGCMs means that we cannot confidently estimate the equilibrium climate sensitivity of an AOGCM without running it to equilibrium. The CMIP5 results suggest that the equilibrium climate sensitivity maybe systematically underestimated by extrapolation of the first $20 \mathrm{yr}$ of an abrupt $4 \mathrm{xCO}_{2} \mathrm{ex}-$ periment. However, there may be further curvature on longer (millennia) time scales (section 6; Senior and Mitchell 2000; Li et al. 2013) that we are unable to assess across models. We would be glad to see other modeling centers extend their $4 \mathrm{xCO}_{2}$ simulations to test the robustness of the linear forcing-feedback paradigm on longer time scales. In contrast to Armour et al. (2013) and Frölicher et al. (2014), we argue that the nonlinearity does not represent a bias in the Gregory et al. (2004) regression method; our interpretation is that when the system is nonlinear the simple linear forcingfeedback concept breaks down. Still, the linear Gregory method applied equally across models retains its utility since it can quantify the main sources of forcing and feedback uncertainty (Andrews et al. 2012a), which in turn explains most of the spread in model projections for the twenty-first century for a given scenario (Forster et al. 2013).

The climate feedback parameter $\alpha$ can be estimated from climate change in response to time-dependent forcing if $\alpha$ is assumed to be constant (Murphy 1995; Gregory et al. 2004). A strong dependence of climate feedbacks on the pattern of SST change therefore raises a question about the applicability of estimates of climate sensitivity derived from the historical record (e.g., Gregory and Forster 2008; Otto et al. 2013). Where on the $(N, \Delta T)$ curve does the observed estimate of climate feedback lie? If the SST change evolves in the future with patterns different from those of the twentieth century then it is conceivable that real-world estimates of climate feedbacks may not be representative of longterm change (Armour et al. 2013; Rose et al. 2014). Further work determining how feedbacks and SST patterns, including the role of coupled atmosphere-ocean variability in the observed record, have evolved over the twentieth century and how they relate to long-term climate change would be valuable.

The equilibrium climate sensitivity is useful as information on committed warming, but it is not the most useful concept for quantifying and comparing climate responses to time-dependent forcing. Improved physical understanding will come from shifting focus onto transient forcings, feedbacks, and ocean heat uptake, which jointly determine the rate and magnitude of timedependent climate change. There would be value in further research examining the effect of ocean heat uptake and transport on the evolution of surface warming patterns (e.g., Woollings et al. 2012; Winton et al. 2013; Rose et al. 2014) in view of their influence, which we have elucidated, on climate feedback.

Acknowledgments. This work was supported by the Joint DECC/Defra Met Office Hadley Centre Climate Programme (GA01101) and (for JMG) by the NCASClimate program. MJW was additionally supported by the European Union Seventh Framework Programme (FP7/2007-2013) under Grant Agreement 244067 via the EU Cloud Intercomparison and Process Study Evaluation project (EUCLIPSE). We thank W. Ingram, J. F. B. Mitchell, and A. Bodas-Salcedo for useful comments on an earlier manuscript. We acknowledge the World Climate Research Programme's Working Group on Coupled Modelling, which is responsible for CMIP, and we thank the climate modelling groups (listed in Table 1 of this paper) for producing and making available their model output. For CMIP, the U.S. Department of Energy's Program for Climate Model Diagnosis and Intercomparison provides coordinating support and led development of software infrastructure in partnership with the Global Organization for Earth System Science Portals.

\section{REFERENCES}

Andrews, T., and M. A. Ringer, 2014: Cloud feedbacks, rapid adjustments, and the forcing-response relationship in a transient $\mathrm{CO}_{2}$ reversibility scenario. J. Climate, 27, 1799-1818, doi:10.1175/JCLI-D-13-00421.1.

— J. J. M. Gregory, M. J. Webb, and K. E. Taylor, 2012a: Forcing, feedbacks and climate sensitivity in CMIP5 coupled atmosphereocean climate models. Geophys. Res. Lett., 39, L09712, doi:10.1029/ 2012 GL051607.

_ and Coauthors, 2012b: Sensitivity of an Earth system climate model to idealized radiative forcing. Geophys. Res. Lett., 39, L10702, doi:10.1029/2012GL051942.

Armour, K. C., C. M. Bitz, and G. H. Roe, 2013: Time-varying climate sensitivity from regional feedbacks. J. Climate, 26, 4518-4534, doi:10.1175/JCLI-D-12-00544.1.

Block, K., and T. Mauritsen, 2013: Forcing and feedback in the MPIESM-LR coupled model under abruptly quadrupled $\mathrm{CO}_{2}$. J. Adv. Model. Earth Syst., 5, 676-691, doi:10.1002/jame.20041. 
Bouttes, N., J. M. Gregory, and J. A. Lowe, 2013: The reversibility of sea level rise. J. Climate, 26, 2502-2513, doi:10.1175/ JCLI-D-12-00285.1.

Charney, J. G., and Coauthors, 1979: Carbon dioxide and climate: A scientific assessment. National Academy of Sciences Rep., $22 \mathrm{pp}$.

Church, J. A., and Coauthors, 2011: Revisiting the Earth's sea-level and energy budgets from 1961 to 2008. Geophys. Res. Lett., 38, L18601, doi:10.1029/2011GL048794.

Clement, A. C., R. Seager, M. A. Cane, and S. E. Zebiak, 1996: An ocean dynamical thermostat. J. Climate, 9, 2190-2196, doi:10.1175/1520-0442(1996)009<2190:AODT>2.0.CO;2.

Collins, M., and Coauthors, 2010: The impact of global warming on the tropical Pacific Ocean and El Niño. Nat. Geosci., 3, 391397, doi:10.1038/ngeo868.

Colman, R., and B. McAvaney, 2009: Climate feedbacks under a very broad range of forcing. Geophys. Res. Lett., 36, L01702, doi:10.1029/2008GL036268.

Danabasoglu, G., and P. R. Gent, 2009: Equilibrium climate sensitivity: Is it accurate to use a slab ocean model? J. Climate, 22, 2494-2499, doi:10.1175/2008JCLI2596.1.

Forster, P. M., T. Andrews, P. Good, J. M. Gregory, L. S. Jackson, and M. Zelinka, 2013: Evaluating adjusted forcing and model spread for historical and future scenarios in the CMIP5 generation of climate models. J. Geophys. Res., 118, 1139-1150, doi:10.1002/jgrd.50174.

Frölicher, T. L., M. Winton, and J. L. Sarmiento, 2014: Continued global warming after $\mathrm{CO}_{2}$ emissions stoppage. Nat. Climate Change, 4, 40-44, doi:10.1038/nclimate2060.

Geoffroy, O., D. Saint-Martin, G. Bellon, A. Voldoire, D. J. L. Olivié, and S. Tytéca, 2013: Transient climate response in a two-layer energy-balance model. Part II: Representation of the efficacy of deep-ocean heat uptake and validation for CMIP5 AOGCMs. J. Climate, 26, 1859-1876, doi:10.1175/ JCLI-D-12-00196.1.

Gregory, J. M., and P. Forster, 2008: Transient climate response estimated from radiative forcing and observed temperature change. J. Geophys. Res., 113, D23105, doi:10.1029/2008JD010405.

— , and M. J. Webb, 2008: Tropospheric adjustment induces a cloud component in $\mathrm{CO}_{2}$ forcing. J. Climate, 21, 58-71, doi:10.1175/2007JCLI1834.1.

— - and Coauthors, 2004: A new method for diagnosing radiative forcing and climate sensitivity. Geophys. Res. Lett., 31, L03205, doi:10.1029/2003GL018747.

Hansen, J., and Coauthors, 2005: Efficacy of climate forcings. J. Geophys. Res., 110, D18104, doi:10.1029/2005JD005776.

Held, I. M., M. Winton, K. Takahashi, T. Delworth, F. Zeng, and G. K. Vallis, 2010: Probing the fast and slow components of global warming by returning abruptly to preindustrial forcing. J. Climate, 23, 2418-2427, doi:10.1175/2009JCLI3466.1.

Kiehl, J. T., 1994: On the observed near cancellation between longwave and shortwave cloud forcing in tropical regions. J. Climate, 7, 559-565, doi:10.1175/1520-0442(1994)007<0559: OTONCB $>2.0 . \mathrm{CO} ; 2$.

Li, C., J.-S. von Storch, and J. Marotzke, 2013: Deep-ocean heat uptake and equilibrium climate response. Climate Dyn., 40, 1071-1086, doi:10.1007/s00382-012-1350-z.

Ma, J., and J.-Y. Yu, 2014: Linking centennial surface warming patterns in the equatorial Pacific to the relative strengths of the Walker and Hadley circulations. J. Atmos. Sci., 71, 3454 3464, doi:10.1175/JAS-D-14-0028.1.

Meraner, K., T. Mauritsen, and A. Voigt, 2013: Robust increase in equilibrium climate sensitivity under global warming. Geophys. Res. Lett., 40, 5944-5948, doi:10.1002/2013GL058118.

Murphy, J. M., 1995: Transient response of the Hadley Centre coupled ocean-atmosphere model to increasing carbon dioxide. Part III: Analysis of global-mean response using simple models. J. Climate, 8, 496-514, doi:10.1175/ 1520-0442(1995)008<0496:TROTHC >2.0.CO;2.

Otto, A., and Coauthors, 2013: Energy budget constraints on climate response. Nat. Geosci., 6, 415-416, doi:10.1038/ ngeo1836.

Rose, B. E. J., K. C. Armour, D. S. Battisti, N. Feldl, and D. D. B. Koll, 2014: The dependence of transient climate sensitivity and radiative feedbacks on the spatial pattern of ocean heat uptake. Geophys. Res. Lett., 41, 1071-1078, doi:10.1002/ 2013 GL058955.

Senior, C. A., and J. F. B. Mitchell, 2000: The time-dependence of climate sensitivity. Geophys. Res. Lett., 27, 2685-2688, doi:10.1029/2000GL011373.

Shine, K. P., and P. M. D. Forster, 1999: The effect of human activity on radiative forcing of climate change: A review of recent developments. Global Planet. Change, 20, 205-225, doi:10.1016/S0921-8181(99)00017-X.

Soden, B. J., and I. M. Held, 2006: An assessment of climate feedbacks in coupled ocean-atmosphere models. J. Climate, 19, 3354-3360, doi:10.1175/JCLI3799.1.

— A. J. Broccoli, and R. S. Hemler, 2004: On the use of cloud forcing to estimate cloud feedback. J. Climate, 17, 3661-3665, doi:10.1175/1520-0442(2004)017<3661:OTUOCF>2.0.CO;2. , I. M. Held, R. Colman, K. M. Shell, J. T. Kiehl, and C. A. Shields, 2008: Quantifying climate feedbacks using radiative kernels. J. Climate, 21, 3504-3520, doi:10.1175/ 2007JCLI2110.1.

Taylor, K. E., M. Crucifix, P. Braconnot, C. D. Hewitt, C. Doutriaux, A. J. Broccoli, J. F. B. Mitchell, and M. J. Webb, 2007: Estimating shortwave radiative forcing and response in climate models. J. Climate, 20, 2530-2543, doi:10.1175/ JCLI4143.1.

Williams, K. D., W. J. Ingram, and J. M. Gregory, 2008: Time variation of effective climate sensitivity in GCMs. J. Climate, 21, 5076-5090, doi:10.1175/2008JCLI2371.1.

Winton, M., K. Takahashi, and I. M. Held, 2010: Importance of ocean heat uptake efficacy to transient climate change. J. Climate, 23, 2333-2344, doi:10.1175/2009JCLI3139.1.

— , S. M. Griffies, B. L. Samuels, J. L. Sarmiento, and T. L. Frölicher, 2013: Connecting changing ocean circulation with changing climate. J. Climate, 26, 2268-2278, doi:10.1175/ JCLI-D-12-00296.1.

Woollings, T., J. M. Gregory, J. G. Pinto, M. Reyers, and D. J. Brayshaw, 2012: Response of the North Atlantic storm track to climate change shaped by ocean-atmosphere coupling. Nat. Geosci., 5, 313-317, doi:10.1038/ngeo1438.

Zelinka, M. D., S. A. Klein, K. E. Taylor, T. Andrews, M. J. Webb, J. M. Gregory, and P. M. Forster, 2013: Contributions of different cloud types to feedbacks and rapid adjustments in CMIP5. J. Climate, 26, 5007-5027, doi:10.1175/ JCLI-D-12-00555.1. 